\title{
Detailed heterogeneous oxidation of soot surfaces in a particle-resolved aerosol model
}

\author{
J. C. Kaiser ${ }^{1, *}$, N. Riemer ${ }^{2}$, and D. A. Knopf ${ }^{3}$ \\ ${ }^{1}$ Department of Physics and Astronomy, Stony Brook University, Stony Brook, NY, USA \\ ${ }^{2}$ Department of Atmospheric Sciences, University of Illinois at Urbana-Champaign, Urbana, IL, USA \\ ${ }^{3}$ Institute for Terrestrial and Planetary Atmospheres, School of Marine and Atmospheric Sciences, Stony Brook University, \\ Stony Brook, NY, USA \\ *currently at: Department of Physics and Astronomy, Universität Würzburg, Würzburg, Germany
}

Received: 19 January 2011 - Published in Atmos. Chem. Phys. Discuss.: 10 February 2011

Revised: 27 April 2011 - Accepted: 30 April 2011 - Published: 12 May 2011

\begin{abstract}
Using the particle-resolved aerosol model PartMC-MOSAIC, we simulate the heterogeneous oxidation of a monolayer of polycyclic aromatic hydrocarbons (PAHs) on soot particles in an urban atmosphere. We focus on the interaction of the major atmospheric oxidants $\left(\mathrm{O}_{3}, \mathrm{NO}_{2}, \mathrm{OH}\right.$, and $\mathrm{NO}_{3}$ ) with PAHs and include competitive co-adsorption of water vapour for a range of atmospheric conditions. For the first time detailed heterogeneous chemistry based on the Pöschl-Rudich-Ammann (PRA) framework is modelled on soot particles with a realistic size distribution and a continuous range of chemical ages. We find PAH half-lives, $\tau_{1 / 2}$, on the order of seconds during the night, when the PAHs are rapidly oxidised by the gas-surface reaction with $\mathrm{NO}_{3}$. During the day, $\tau_{1 / 2}$ is on the order of minutes and determined mostly by the surface layer reaction of PAHs with adsorbed $\mathrm{O}_{3}$. Such short half-lives of surface-bound PAHs may lead to efficient conversion of hydrophobic soot into more hygroscopic particles, thus increasing the particles' aerosol-cloud interaction potential. Despite its high reactivity $\mathrm{OH}$ appears to have a negligible effect on PAH degradation which can be explained by its very low concentration in the atmosphere. An increase of relative humidity (RH) from $30 \%$ to $80 \%$ increases PAH half-lives by up to $50 \%$ for daytime degradation and by up to $100 \%$ or more for nighttime degradation. Uptake coefficients, averaged over the particle population, are found to be relatively constant over time for $\mathrm{O}_{3}\left(\sim 2 \times 10^{-7}\right.$ to $\left.\sim 2 \times 10^{-6}\right)$ and $\mathrm{NO}_{2}\left(\sim 5 \times 10^{-6}\right.$ to $\left.\sim 10^{-5}\right)$ at the different levels of $\mathrm{NO}_{\mathrm{x}}$ emissions and $\mathrm{RH}$ considered in this study. In contrast, those for $\mathrm{OH}$ and $\mathrm{NO}_{3}$ depend strongly on the surface concentration of PAHs. We do not find a significant
\end{abstract}

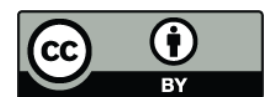

Correspondence to: N. Riemer (nriemer@illinois.edu) influence of heterogeneous reactions on soot particles on the gas phase composition. The derived half-lives of surfacebound PAHs and the time and particle population averaged uptake coefficients for $\mathrm{O}_{3}$ and $\mathrm{NO}_{2}$ presented in this paper can be used as parameterisations for the treatment of heterogeneous chemistry in large-scale atmospheric chemistry models.

\section{Introduction}

Organic aerosol particles are abundant in the atmosphere (Maria et al., 2004; Jimenez et al., 2009) and can affect human health upon respiration (Finlayson-Pitts and Pitts, 1997; Pöschl, 2002; Bernstein et al., 2004) as well as global and regional climate via absorption or scattering of light and the ability to act as cloud condensation or ice nuclei (e.g., Ramanathan et al., 2001; Kanakidou et al., 2005; Forster et al., 2007; Knopf et al., 2010). An ubiquitous type of such particles is soot, which is found in diesel engine exhaust, for example, due to incomplete combustion of the fuel (FinlaysonPitts and Pitts, 2000).

During atmospheric transport particles can undergo physical and chemical changes by interaction with gas phase species (Weingartner et al., 1997; Wang et al., 2010), processes collectively known as aging. For example, condensation of additional organic material may lead to the formation of secondary organic aerosol (e.g., Seinfeld and Pandis, 2006; Rudich et al., 2007; Hallquist et al., 2009; Jimenez et al., 2009) while chemical reactions can also modify the particles' composition (e.g., Rudich, 2003; Maria et al., 2004; Rudich et al., 2007).

Published by Copernicus Publications on behalf of the European Geosciences Union. 
Among the least understood processes affecting particle composition are heterogeneous oxidation reactions involving trace gases such as ozone $\left(\mathrm{O}_{3}\right)$, nitrogen dioxide $\left(\mathrm{NO}_{2}\right)$ and the hydroxyl $(\mathrm{OH})$ and nitrate $\left(\mathrm{NO}_{3}\right)$ radicals (Rudich et al., 2007; Kolb et al., 2010). Reaction mechanisms and products that determine this so-called chemical aging are still poorly known, so that modelling of the processes remains difficult. However, laboratory studies show that heterogeneous reactions do modify a particle's surface composition and can thereby change its physico-chemical properties (Rudich, 2003; Knopf et al., 2006; Rudich et al., 2007; Finlayson-Pitts, 2009; Kolb et al., 2010). For example, certain substances found on particle surfaces become mutagenic upon nitration, i.e. reaction with $\mathrm{NO}_{\mathrm{x}}$ (Finlayson-Pitts and Pitts, 2000; Reisen and Arey, 2005). Also, oxidation of carbonaceous and organic aerosol particle surfaces can lead to increased hygroscopicity, enhancing the particles' ability to act as cloud condensation nuclei (Kotzick et al., 1997; Chughtai et al., 1999; Broekhuizen et al., 2004; Huff Hartz et al., 2005; Petters et al., 2006; Shilling et al., 2007; Liu et al., 2010).

An important class of surface-bound organics found in the analysis of soot particles are polycyclic aromatic hydrocarbons (PAHs) (Rogge et al., 1993; Pakbin et al., 2009; El Haddad et al., 2009; Kashiwakura and Sakamoto, 2010), some of which are toxic or carcinogenic (Finlayson-Pitts and Pitts, 2000). PAHs, such as benzo[a]pyrene or pyrene, are generated along with the soot particles during combustion and some of them subsequently condense on the particles (Finlayson-Pitts and Pitts, 2000; Seinfeld and Pandis, 2006). These chemicals can be regarded as similar to soot in terms of their molecular structure on soot surfaces where they form graphene-like layers (Pöschl, 2005; Cain et al., 2010). Numerous laboratory and modelling studies have been conducted to determine the mechanisms and parameters of heterogeneous reactions between soot or soot-like substances and atmospheric oxidants (Rogaski et al., 1997; Gerecke et al., 1998; Bertram et al., 2001; Pöschl et al., 2001; Arens et al., 2002; Kwamena et al., 2004; Molina et al., 2004; Gross and Bertram, 2008, and references therein). These studies found that $\mathrm{OH}$ and $\mathrm{NO}_{3}$ react very efficiently with PAH surfaces according to a first-order reaction rate (Bertram et al., 2001; Gross and Bertram, 2008). In contrast, $\mathrm{O}_{3}$ and $\mathrm{NO}_{2}$ show a Langmuir-Hinshelwood type uptake behaviour whose pseudo-first-order reaction rate is characterised by a dependence on gas phase concentration and available reaction sites (Pöschl et al., 2001; Arens et al., 2002).

Pöschl and coworkers developed a theoretical framework for aerosol and cloud surface chemistry and gas-particle interactions (Pöschl et al., 2007; Ammann and Pöschl, 2007), termed Pöschl-Rudich-Ammann (PRA) framework, to describe dynamically the interactions at the gas-particle interface that govern heterogeneous chemistry. The PRA framework employs a flux based approach to describe mass transfer and chemical reactions between gas phase, surface layer, and particle bulk. This allows for a complete physical description of heterogeneous kinetics, e.g. of the uptake coefficients' temporal evolution, by knowledge of the basic physico-chemical parameters such as accommodation coefficients, desorption lifetimes, and reaction rate coefficients.

Previous studies have successfully employed the PRA framework to reproduce experimental results (Ammann and Pöschl, 2007) and to address scenarios with a complexity beyond current laboratory measurement limitations (Shiraiwa et al., 2009). Springmann et al. (2009) improved upon this by coupling the PRA mechanism to a gas phase chemical mechanism to account for changes in atmospheric gas phase composition due to the diurnal photochemical cycle and heterogeneous chemistry.

All the studies using the PRA framework found that uptake coefficients of $\mathrm{O}_{3}$ and $\mathrm{NO}_{2}$ on individual PAH-coated soot particles can vary over several orders of magnitude within simulation times on the order of one day. This is in sharp contrast to some large-scale models that use reaction rate coefficients which depend only on the amount of available particle surface area (e.g., Bey et al., 2001; Tie et al., 2001; Matthias et al., 2009, note that the terminology concerning uptake or rate coefficients is different in these three papers). However, in existing aerosol models it is usually not possible to represent aerosol particles of different processing stages. Thus, the effect of chemical aging on heterogeneous kinetics is difficult to incorporate and commonly neglected.

In the present paper we address this problem by investigating detailed heterogeneous chemistry using a particleresolved aerosol model framework. Our study makes the following contributions: (1) We developed a model framework that employs the PRA mechanism within the particleresolved model PartMC-MOSAIC (Particle Monte Carlo model, coupled to the MOdel for Simulating Aerosol Interactions and Chemistry, Riemer et al., 2009; Zaveri et al., 2008). This includes the heterogeneous interactions of the PAHcoated soot particles with four major atmospheric oxidants $\left(\mathrm{O}_{3}, \mathrm{NO}_{2}, \mathrm{OH}, \mathrm{NO}_{3}\right)$ and the competitive co-adsorption of water vapour in an urban polluted environment; (2) Using this model we explicitly derived uptake coefficients for the oxidant species both on a per-particle level and on a particle population level, i.e. averaged over all particles in the modelled population. (3) Furthermore, we investigated the process-resolved lifetimes of condensed phase PAHs on soot at different levels of $\mathrm{NO}_{\mathrm{x}}$ emissions.

This paper is organised as follows. In Sect. 2 we review the underlying theory for the treatment of heterogeneous chemistry in our model and present the governing equations for the coupled model. We describe the simulation parameters and assumptions in Sect. 3. Section 4 presents the results and their discussion, and we conclude our paper in Sect. 5. 


\section{Model description}

\subsection{PartMC-MOSAIC}

PartMC-MOSAIC (Riemer et al., 2009; Zaveri et al., 2005a,b, 2008) is a particle-resolved model that explicitly resolves and tracks the composition of many individual aerosol particles within a well-mixed computational volume that represents a much larger, well-mixed air parcel of interest. Here we use PartMC-MOSAIC in a reduced mode in order to focus on isolating the effects of heterogeneous chemistry. We include stochastic particle emissions and a deterministic treatment for the gas phase chemistry (via the carbon bond mechanism CBM-Z, Zaveri and Peters, 1999) to simulate the emission of soot particles coated with PAHs and the particles' subsequent processing. Chemical reactions are represented by differential equations which are solved numerically by the solver DLSODES (2003 version of the Livermore Solver for Ordinary Differential Equations with general Sparse Jacobian matrix, Hindmarsh, 1983; Eisenstat et al., 1982, 1977).

Particle emissions are handled as follows (Riemer et al., 2009): Since we are using a finite number of particles to represent the aerosol population a finite number of emitted particles has to be added to the computational volume at each time step. We determine the number of emitted particles by assuming that the particle emissions are memoryless, i.e. the emission of each particle is uncorrelated with the emission of any other particle. Under this assumption the number of emitted particles added per time step will be Poisson distributed with a mean that corresponds to a prescribed continuous emission rate. As particles are constantly added through emissions and particle loss processes are not considered, this number would continuously increase. Thus, half of the particles are selected randomly and discarded once their total number doubles compared to the initial value. Note that this removal of particles does not lead to a difference in soot concentration because the computational volume is reduced at the same time. Furthermore, each emitted particle is taken to have a prescribed composition and a diameter sampled from a given lognormal distribution.

To treat the heterogeneous reactions we extended PartMCMOSAIC for the purpose of this study to also include adsorption and desorption of gas molecules on particle surfaces and heterogeneous reactions on those surfaces. Our implementation of these processes is based on the PRA framework described in the next section.

\subsection{PRA framework}

Within the PRA framework (Pöschl et al., 2007; Ammann and Pöschl, 2007) the gas phase, a double-layer surface, and the particle bulk are connected by mass fluxes. These are determined by physical and chemical interactions of species in the respective compartments as shown in Fig. 1.

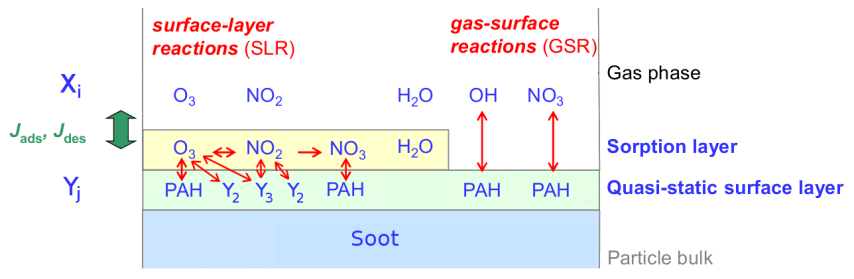

Fig. 1. Illustration of the PRA framework as used in this study (adapted from Shiraiwa et al., 2009). Fluxes of volatile species $\mathrm{X}_{i}$ $\left(\mathrm{O}_{3}, \mathrm{NO}_{2}, \mathrm{H}_{2} \mathrm{O}, \mathrm{OH}\right.$, and $\left.\mathrm{NO}_{3}\right)$ are indicated by the green arrow, reactions by the red arrows. The soot particles are coated with a monolayer of non-volatile species $\mathrm{Y}_{j}$ (only the reactive ones, $\mathrm{PAH}$, Y2, and Y3, are shown here).

The model surface consists of a sorption layer and a quasistatic layer and can be regarded as the core feature of the PRA framework. It permits modelling of two types of heterogeneous reactions in parallel, namely those following Langmuir-Hinshelwood type kinetics and those following Eley-Rideal type kinetics. Both terms originally refer to catalytic reactions but the mechanisms involved are very similar. Langmuir-Hinshelwood type reactions are characterised by adsorption of gas molecules on the particles and subsequent surface reactions, either between two adsorbing gas species or between adsorbed gas molecules and the surface itself. In Eley-Rideal type reactions, the adsorption step is skipped so that a gas molecule directly reacts with an adsorbed one or with species in the quasi-static surface layer. We will refer to the two reaction types as surface layer reactions (SLRs) and gas-surface reactions (GSRs), respectively. For our simulations we assume that $\mathrm{O}_{3}$ and $\mathrm{NO}_{2}$ undergo SLRs, that $\mathrm{OH}$ and $\mathrm{NO}_{3}$ undergo GSRs, and that $\mathrm{H}_{2} \mathrm{O}$ only adsorbs and desorbs in the sorption layer without any reactions (Shiraiwa et al., 2009). Note that very recently Shiraiwa et al. (2011) showed that $\mathrm{O}_{3}$ does actually not follow simple Langmuir-Hinshelwood kinetics. Instead, it either desorbs rapidly or dissociates into $\mathrm{O}$ atoms and long-lived reactive oxygen intermediates upon adsorption on a PAH surface (Shiraiwa et al., 2011). These intermediates can subsequently react with the PAHs (Shiraiwa et al., 2011). However, for the purpose of our study the Langmuir- Hinshelwood description is detailed enough to adequately represent the $\mathrm{O}_{3}-\mathrm{PAH}$ interaction.

\subsubsection{Governing equations}

In this work we assume that $N_{\mathrm{v}}=5$ volatile gas phase species $\left(\mathrm{X}_{i}(\mathrm{~g}), i=1, \ldots, N_{\mathrm{v}}\right)$ participate in heterogeneous processes. These are $\mathrm{O}_{3}, \mathrm{NO}_{2}, \mathrm{OH}, \mathrm{NO}_{3}$, and $\mathrm{H}_{2} \mathrm{O}$ (note that $\mathrm{HONO}$ is considered only as a reaction product and assumed to desorb readily). Some of these species (see Table 1) can be adsorbed on the particle surface where they exist as (volatile) sorption layer species $\left(\mathrm{X}_{i}(\mathrm{~s}), i=1, \ldots, N_{\mathrm{v}}\right)$. Moreover, we 
Table 1. List of volatile species considered here that take part in heterogeneous reactions (cf. Table 2) and corresponding processes that they participate in. SLR denotes surface layer reactions and GSR stands for gas-surface reactions. $\mathrm{NO}_{3}$ does not adsorb onto the particles from the gas phase but is produced in the sorption layer by SLR6.

\begin{tabular}{lcccc}
\hline Species & Adsorption & Desorption & SLR & GSR \\
\hline $\mathrm{O}_{3}$ & $\times$ & $\times$ & $\times$ & - \\
$\mathrm{NO}_{2}$ & $\times$ & $\times$ & $\times$ & - \\
$\mathrm{H}_{2} \mathrm{O}$ & $\times$ & $\times$ & - & - \\
$\mathrm{OH}$ & - & - & - & $\times$ \\
$\mathrm{NO}_{3}(\mathrm{~g})$ & - & - & - & $\times$ \\
$\mathrm{NO}_{3}(\mathrm{~s})$ & - & $\times$ & $\times$ & - \\
\hline
\end{tabular}

Table 2. Heterogeneous reactions implemented in PartMCMOSAIC with corresponding reaction rate coefficients and reaction probabilities.

\begin{tabular}{|c|c|}
\hline Surface layer reaction & Rate constant $\left[\mathrm{cm}^{2} \mathrm{~s}^{-1}\right]$ \\
\hline $\begin{array}{l}(\mathrm{SLR} 1) \mathrm{O}_{3}(\mathrm{~s})+\mathrm{PAH}(\mathrm{ss}) \rightarrow \mathrm{Y}_{2}(\mathrm{ss}) \\
(\mathrm{SLR} 2) \mathrm{O}_{3}(\mathrm{~s})+\mathrm{Y}_{2}(\mathrm{ss}) \rightarrow \mathrm{Y}_{3}(\mathrm{ss}) \\
(\mathrm{SLR} 3) \mathrm{O}_{3}(\mathrm{~s})+\mathrm{Y}_{3}(\mathrm{ss}) \rightarrow \mathrm{Y}_{4}(\mathrm{ss}) \\
(\mathrm{SLR} 4) \mathrm{NO}_{2}(\mathrm{~s})+\mathrm{Y}_{2}(\mathrm{ss}) \rightarrow \mathrm{Y}_{5}(\mathrm{ss}) \\
(\mathrm{SLR} 5) \mathrm{NO}_{2}(\mathrm{~s})+\mathrm{Y}_{3}(\mathrm{ss}) \rightarrow \mathrm{HONO}(\mathrm{g}) \\
(\mathrm{SLR} 6) \mathrm{O}_{3}(\mathrm{~s})+\mathrm{NO}_{2}(\mathrm{~s}) \rightarrow \mathrm{NO}_{3}(\mathrm{~s}) \\
(\mathrm{SLR})) \mathrm{NO}_{3}(\mathrm{~s})+\mathrm{PAH}(\mathrm{ss}) \rightarrow \mathrm{Y}_{6}(\mathrm{ss})\end{array}$ & $\begin{array}{l}k_{\mathrm{O}_{3}, \mathrm{PAH}}=2.7 \times 10^{-17 \mathrm{a}} \\
k_{\mathrm{O}_{3}, \mathrm{Y}_{2}}=2.7 \times 10^{-19 \mathrm{a}, \mathrm{b}} \\
k_{\mathrm{O}_{3}, \mathrm{Y}_{3}}=2.7 \times 10^{-21 \mathrm{a}, \mathrm{b}} \\
k_{\mathrm{NO}_{2}, \mathrm{Y}_{2}}=7.0 \times 10^{-18 \mathrm{~b}} \\
k_{\mathrm{NO}_{2}, \mathrm{Y}_{3}}=7.5 \times 10^{-21 \mathrm{c}, \mathrm{d}} \\
k_{\mathrm{O}_{3}, \mathrm{NO}_{2}}=5 \times 10^{-17 \mathrm{a}} \\
k_{\mathrm{NO}_{3}, \mathrm{PAH}}=5 \times 10^{-15 \mathrm{a}}\end{array}$ \\
\hline Gas surface reaction & Probability \\
\hline $\begin{array}{l}(\mathrm{GSR} 1) \mathrm{OH}(\mathrm{g})+\mathrm{PAH}(\mathrm{ss}) \rightarrow \mathrm{Y}_{7}(\mathrm{ss}) \\
(\mathrm{GSR} 2) \mathrm{NO}_{3}(\mathrm{~g})+\mathrm{PAH}(\mathrm{ss}) \rightarrow \mathrm{Y}_{8}(\mathrm{ss})\end{array}$ & $\begin{array}{l}\gamma_{\mathrm{OH}, \mathrm{PAH}}=0.32^{\mathrm{e}} \\
\gamma_{\mathrm{NO}_{3}, \mathrm{PAH}}=0.79^{\mathrm{f}}\end{array}$ \\
\hline
\end{tabular}

a Shiraiwa et al. (2009); ${ }^{\mathrm{b}}$ Ammann and Pöschl (2007); ${ }^{\mathrm{c}}$ Springmann et al. (2009);

d Ammann et al. (1998); ${ }^{\mathrm{e}}$ Bertram et al. (2001); ${ }^{\mathrm{f}}$ Gross and Bertram (2008)

consider $N_{\mathrm{nv}}=8$ non-volatile species in the quasi-static surface layer $\left(\mathrm{Y}_{j}(\mathrm{ss}), j=1, \ldots, N_{\mathrm{nv}}\right.$; we identify $\mathrm{Y}_{1}$ (ss) with the $\mathrm{PAHs}$ ). Concentrations are denoted by square brackets with an index, e.g. $\left[\mathrm{X}_{i}\right]_{\mathrm{S}}$ for a surface concentration in the sorption layer. The volatile species $\mathrm{X}_{i}$ undergo $N_{\mathrm{SLR}}=7$ SLRs and $N_{\mathrm{GSR}}=2$ GSRs with non-volatile PAHs and other species of the quasi-static surface layer, producing non-volatile species $\mathrm{Y}_{2}-\mathrm{Y}_{8}$ (see Tables 1 and 2). Quantities that are defined on a per-particle basis are marked by superscript $l\left(l=1, \ldots, N_{\mathrm{p}}\right.$, where $N_{\mathrm{p}}$ is the number of particles), e.g. $\left[\mathrm{Y}_{j}\right]_{\mathrm{ss}}^{l}$ for the surface concentration of $\mathrm{Y}_{j}$ in the quasi-static surface layer of particle $l$.

The model solves the following equations for surface and gas phase concentrations that are influenced by heterogeneous chemistry:

$$
\begin{aligned}
& \frac{d\left[\mathrm{X}_{i}\right]_{\mathrm{s}}^{l}}{d t}=\underbrace{J_{\mathrm{ads}, \mathrm{X}_{i}}^{l}}_{\text {adsorption flux }}-\underbrace{J_{\mathrm{des}, \mathrm{X}_{i}}^{l}}_{\text {desorption flux }}+\underbrace{P_{\mathrm{X}_{i}}^{l}-L_{\mathrm{X}_{i}}^{l}}_{\text {chemical production and loss }} \\
& i=1, \ldots, N_{\mathrm{v}}, l=1, \ldots, N_{\mathrm{p}}, \\
& \frac{d\left[\mathrm{Y}_{j}\right]_{\mathrm{SS}}^{l}}{d t}=\underbrace{P_{\mathrm{Y}_{j}}^{l}-L_{\mathrm{Y}_{j}}^{l}}_{\text {chemical production and loss }} \\
& j=1, \ldots, N_{\mathrm{nv}}, l=1, \ldots, N_{\mathrm{p}}, \\
& \frac{d\left[\mathrm{X}_{i}\right]_{\mathrm{g}}}{d t}=-\sum_{l=1}^{N_{\mathrm{p}}} \gamma_{\mathrm{X}_{i}}^{\prime l} J_{\mathrm{coll}, \mathrm{X}_{i}}^{l} \times \frac{S^{l}}{V}, \quad i=1, \ldots, N_{\mathrm{v}}
\end{aligned}
$$

Here, $\gamma_{\mathrm{X}_{i}}^{\prime l}$ is the effective uptake coefficient for species $\mathrm{X}_{i}$ on particle $l$ (defined in Eqs. (16) and (18) below), $J_{\text {coll, } \mathrm{X}_{i}}^{l}$ the collision flux of $\mathrm{X}_{i}$ molecules with that particle, $S^{l}$ the particle's surface area, and $V$ the computational volume. The right-hand side terms of Eqs. (1)-(3) are explained in detail in the following sections. Note that the concentrations $\left[\mathrm{X}_{i}\right]_{\mathrm{g}}$ are also influenced by gas phase reactions - such as photochemical reactions affecting $\left[\mathrm{O}_{3}\right]_{\mathrm{g}}$ and $\left[\mathrm{NO}_{2}\right]_{\mathrm{g}}$ - which are included in our model simulations, but not explicitly listed in Eq. (3). Thus, Eq. (3) only represents the contribution of heterogeneous chemistry to their temporal evolution.

\subsubsection{Adsorption and desorption fluxes}

The adsorption flux onto particle $l$, which appears in Eq. (1), is determined by the accommodation coefficient $\alpha_{\mathrm{s}, \mathrm{X}_{i}}^{l}$ and the collision flux $J_{\text {coll, } X_{i}}^{l}$ :

$J_{\mathrm{ads}, \mathrm{X}_{i}}^{l}=\alpha_{\mathrm{s}, \mathrm{X}_{i}}^{l} J_{\mathrm{coll}, \mathrm{X}_{i}}^{l}$,

where

$\alpha_{\mathrm{s}, X_{i}}^{l}=\alpha_{\mathrm{s}, 0, X_{i}}\left(1-\theta_{\mathrm{s}}^{l}\right)$.

Here, $\alpha_{\mathrm{s}, 0, \mathrm{X}_{i}}$ stands for the accommodation coefficient of an adsorbate-free surface and the total sorption layer coverage $\theta_{\mathrm{s}}^{l}$ of particle $l$ is given by

$\theta_{\mathrm{s}}^{l}=\sum_{i=1}^{N_{\mathrm{v}}} \theta_{\mathrm{s}, \mathrm{X}_{i}}^{l}=\sum_{i=1}^{N_{\mathrm{v}}} \sigma_{\mathrm{X}_{i}}\left[\mathrm{X}_{i}\right]_{\mathrm{s}}^{l}$,

where the $\sigma_{\mathrm{X}_{i}}$ represent molecular cross sections of the species $\mathrm{X}_{i}$. According to gas kinetic theory the collision flux of $\mathrm{X}_{i}(\mathrm{~g})$ molecules that hits the surface of aerosol particle $l$ can be expressed as

$J_{\mathrm{coll}, \mathrm{X}_{i}}^{l}=\frac{\omega_{\mathrm{X}_{i}}}{4}\left[\mathrm{X}_{i}\right]_{\mathrm{gs}}^{l}$.

Here, $\omega_{\mathrm{X}_{i}}$ denotes the thermal speed of $\mathrm{X}_{i}(\mathrm{~g})$ molecules and $\left[\mathrm{X}_{i}\right]_{\mathrm{gs}}^{l}$ the gas phase concentration close to the surface of particle $l$. 
If the effective uptake coefficient $\gamma_{\mathrm{X}_{i}}^{\prime l}$ (see Eqs. 16 and 18) is less than $10^{-3}$, gas uptake on the particle surface does not significantly deplete the concentration $\left[\mathrm{X}_{i}\right]_{\mathrm{g}}$ close to the particle surface and thus $\left[\mathrm{X}_{i}\right]_{\mathrm{gs}}^{l}=\left[\mathrm{X}_{i}\right]_{\mathrm{g}}$ is a good approximation (Ammann and Pöschl, 2007). In the case of greater $\gamma_{\mathrm{X}_{i}}^{\prime l}$ a gas phase diffusion correction factor has to be applied to account for such changes:

$\left[\mathrm{X}_{i}\right]_{\mathrm{gs}}^{l}=C_{\mathrm{g}, \mathrm{X}_{i}}^{l}\left[\mathrm{X}_{i}\right]_{\mathrm{g}}$

Based on work by Fuchs and Sutugin (1971), it is given in the PRA framework as:

$C_{\mathrm{g}, \mathrm{X}_{i}}^{l}=\frac{1}{1+\gamma_{\mathrm{X}_{i}}^{\prime l} \frac{0.75+0.28 K n_{\mathrm{X}_{i}}^{l}}{K n_{\mathrm{X}_{i}}^{l}\left(1+K n_{\mathrm{X}_{i}}^{l}\right)}}$

The Knudsen number $K n_{\mathrm{X}_{i}}^{l}$ is calculated from the gas phase diffusion coefficient $D_{\mathrm{g}, \mathrm{X}_{i}}$, air pressure $p$, thermal speed of the gas molecules $\omega_{\mathrm{X}_{i}}$ and particle diameter $d_{\mathrm{p}}^{l}$ :

$K n_{\mathrm{X}_{i}}^{l}=\frac{6 D_{\mathrm{g}, \mathrm{X}_{i}}}{p \omega_{\mathrm{X}_{i}} d_{\mathrm{p}}^{l}}$

In the scenarios presented here $\gamma_{\mathrm{X}_{i}}^{\prime l} \leq 10^{-3}$ for $\mathrm{X}_{i}=$ $\mathrm{O}_{3}, \mathrm{NO}_{2}, \mathrm{H}_{2} \mathrm{O}$, i.e. the species which undergo SLRs and water vapour which co-adsorbs but does not react (cf. Table 3). Note that although the effective uptake coefficient of $\mathrm{NO}_{2}$ is initially higher than $10^{-3}$, namely 0.064 , it decreases to $<10^{-3}$ on a time scale much shorter than the model resolution of one minute. In contrast, initially, $\gamma_{\mathrm{X}_{i}}^{\prime l} \gg 10^{-3}$ for the GSRs of PAHs with $\mathrm{X}_{i}=\mathrm{OH}$ and $\mathrm{NO}_{3}$, so that the gas phase correction factor substantially deviates from $C_{\mathrm{g}, \mathrm{X}_{i}}^{l}=1$ in the case of the GSRs considered here.

Adsorbed molecules desorb from the surface after a characteristic average time $\tau_{\mathrm{d}, \mathrm{X}_{i}}$, termed desorption lifetime, if they do not undergo any reactions. The desorption flux (cf. Eq. 1) depends on desorption lifetime and surface concentration:

$J_{\mathrm{des}, \mathrm{X}_{i}}^{l}=\frac{\left[\mathrm{X}_{i}\right]_{\mathrm{s}}^{l}}{\tau_{\mathrm{d}, \mathrm{X}_{i}}}$

\subsubsection{Chemical reactions}

The chemical gain and loss terms are based on concentrations of the reagents and on reaction rate coefficients or reaction probabilities for SLRs and GSRs, respectively. The reactions considered in this study can be found in Table 2 .

Net production in or loss of volatile species from the sorption layer (as used in Eq. 1) is due to both reactions within that layer and reactions with species in the quasi-static surface layer. We therefore distinguish between two types of production and loss terms and designate them by adding the indices "s" and "ss" (as compared to Eq. 1):

$$
P_{\mathrm{s}, \mathrm{s}, \mathrm{X}_{i}}^{l}-L_{\mathrm{s}, \mathrm{s}, \mathrm{X}_{i}}^{l}=\sum_{n=1}^{N_{\mathrm{SLR}}} \sum_{p=1}^{N_{\mathrm{v}}} \sum_{q=1}^{N_{\mathrm{v}}} c_{\mathrm{SLR} n, \mathrm{~s}, \mathrm{X}_{i}} k_{\mathrm{X}_{p}, \mathrm{X}_{q}}\left[\mathrm{X}_{p}\right]_{\mathrm{s}}^{l}\left[\mathrm{X}_{q}\right]_{\mathrm{s}}^{l},
$$

$$
P_{\mathrm{s}, \mathrm{ss}, \mathrm{X}_{i}}^{l}-L_{\mathrm{s}, \mathrm{ss}, \mathrm{X}_{i}}^{l}=\sum_{n=1}^{N_{\mathrm{SLR}}} \sum_{p=1}^{N_{\mathrm{v}}} \sum_{q=1}^{N_{\mathrm{nv}}} c_{\mathrm{SLR} n, \mathrm{~s}, \mathrm{X}_{i}} k_{\mathrm{X}_{p}, \mathrm{Y}_{q}}\left[\mathrm{X}_{p}\right]_{\mathrm{s}}^{l}\left[\mathrm{Y}_{q}\right]_{\mathrm{ss}}^{l} .
$$

Here, $c_{\mathrm{SLR} n, \mathrm{~s}, \mathrm{X}_{i}}$ represent stoichiometric coefficients of $\mathrm{X}_{i}$ in the respective reaction equations. They are positive if $\mathrm{X}_{i}$ is produced in a reaction and negative if it is consumed. $k_{\mathrm{X}_{p}, \mathrm{X}_{q}}$ and $k_{\mathrm{X}_{p}, \mathrm{Y}_{q}}$ denote rate coefficients for reactions between surface species (as given in Table 2). Equation (13) can be written analogously for production and loss of quasi-static surface layer species.

The gas-surface reactions considered here lead to production and loss of species in the quasi-static surface layer (as given in Eq. (2), again with additional indices to specify the reaction type):

$P_{\mathrm{ss}, \mathrm{g}, \mathrm{Y}_{j}}^{l}-L_{\mathrm{ss}, \mathrm{g}, \mathrm{Y}_{j}}^{l}=$

$\sum_{n=1}^{N_{\mathrm{GSR}}} \sum_{p=1}^{N_{\mathrm{v}}} \sum_{q=1}^{N_{\mathrm{nv}}} c_{\mathrm{GSR} n, \mathrm{ss}, \mathrm{Y}_{j}} \gamma_{\mathrm{X}_{p}, \mathrm{Y}_{q}}\left(1-\theta_{\mathrm{s}}^{l}\right) J_{\mathrm{coll}, \mathrm{X}_{p}}^{l} \theta_{\mathrm{ss}, \mathrm{Y}_{q}}^{l}$.

Here, $\gamma \mathrm{X}_{p}, \mathrm{Y}_{q}$ is the (time-independent) elementary reaction probability that measures the fraction of $\mathrm{X}_{p}(\mathrm{~g})$ molecules colliding with molecules $\mathrm{Y}_{q}$ (ss) of the reactive surface that actually undergoes reaction (values for reactions considered in this study are listed in Table 2). $\theta_{\mathrm{ss}, \mathrm{Y}_{q}}^{l}=\sigma_{\mathrm{Y}_{q}}\left[\mathrm{Y}_{q}\right]_{\mathrm{ss}}^{l}$ denotes coverage of the quasi-static surface layer with the reactive species $\mathrm{Y}_{q}$ on particle $l$.

\subsubsection{Effective uptake coefficient}

Due to chemical reactions on the surface a certain fraction of molecules that collide with particle $l$ will be permanently removed from the gas phase. The resulting net flux onto that particle can be written as:

$J_{\text {net, } \mathrm{X}_{i}}^{l}=\gamma_{\mathrm{X}_{i}}^{\prime l} J_{\mathrm{coll}, \mathrm{X}_{i}}^{l}$

The proportionality constant $\gamma_{\mathrm{X}_{i}}^{\prime l}$ is called the effective uptake coefficient.

We deviate from the original nomenclature of the PRA framework here. In the literature, $\gamma$ has commonly been used for systems in which only one reactive gas species was considered and the amount of reactive surface sites was assumed to remain constant during reaction processes. However, the PRA framework allows this parameter to change dynamically because reactive sites may be occupied by adsorbing species or consumed by heterogeneous reactions. Since the uptake coefficient of the PRA framework does reflect such 
Table 3. Physico-chemical parameters for the species interacting with the soot surface in this study.

\begin{tabular}{lllll}
\hline Species $\left(X_{i}\right)$ & $\alpha_{\mathrm{s}, 0, \mathrm{X}_{i}}$ & $\sigma_{\mathrm{X}_{i}}\left[\mathrm{~cm}^{2}\right]$ & $\tau_{\text {des }, \mathrm{X}_{i}}[\mathrm{~s}]$ & $D_{\mathrm{g}, \mathrm{X}_{i}}\left[\mathrm{hPacm}^{2} \mathrm{~s}^{-1}\right]$ \\
\hline $\mathrm{O}_{3}$ & $10^{-3 \mathrm{a}}$ & $1.7 \times 10^{-15 \mathrm{a}}$ & $10^{\mathrm{a}}$ & \\
$\mathrm{NO}_{2}$ & $6.4 \times 10^{-2 \mathrm{~b}}$ & $3.0 \times 10^{-15 \mathrm{c}}$ & $5 \times 10^{-2 \mathrm{a}}$ & \\
$\mathrm{H}_{2} \mathrm{O}$ & $4 \times 10^{-4 \mathrm{~d}}$ & $1.08 \times 10^{-15 \mathrm{e}}$ & $3.6 \times 10^{-4 \mathrm{a}}$ & \\
$\mathrm{OH}$ & - & - & - & $217^{\mathrm{f}}$ \\
$\mathrm{NO}_{3}$ & - & $1.7 \times 10^{-15 \mathrm{~g}}$ & $10^{\mathrm{a}}$ & $107^{\mathrm{h}}$ \\
\hline
\end{tabular}

${ }^{a}$ Shiraiwa et al. (2009); ${ }^{\mathrm{b}}$ Tabor et al. (1994); ${ }^{\mathrm{c}}$ Ammann and Pöschl (2007); ${ }^{\mathrm{d}}$ Rogaski et al. (1997); ${ }^{\mathrm{e}}$ Nishino (2001); ${ }^{\mathrm{f}}$ Ivanov et al. (2007); ${ }^{\mathrm{g}}$ as in Shiraiwa et al. (2009), personal

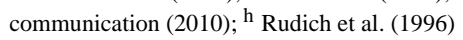

changes we speak of an effective uptake coefficient here and assign the symbol $\gamma_{\mathrm{X}_{i}}^{\prime l}$ to it.

In the case of SLRs, $J_{\text {net, } X_{i}}^{l}$ can be derived as the difference of adsorption and desorption fluxes, so that Eq. (15) can be used to diagnose $\gamma_{\mathrm{X}_{i}}^{\prime l}$. Combining $J_{\text {net, } X_{i}}^{l}=J_{\text {ads, } X_{i}}^{l}-J_{\text {des, }, X_{i}}^{l}$ with Eqs. (4)-(7), (11), and (15) the effective uptake coefficient for a SLR can be written as

$\gamma_{\mathrm{SLR}, \mathrm{X}_{i}}^{\prime l}=\alpha_{\mathrm{s}, 0, \mathrm{X}_{i}}\left(1-\sum_{i=1}^{N_{\mathrm{v}}} \sigma_{\mathrm{X}_{i}}\left[\mathrm{X}_{i}\right]_{\mathrm{s}}^{l}\right)-\frac{4\left[\mathrm{X}_{i}\right]_{\mathrm{S}}^{l}}{\tau_{\mathrm{d}, \mathrm{X}_{i}} \omega_{\mathrm{X}_{i}}\left[\mathrm{X}_{i}\right]_{\mathrm{gs}}^{l}}$,

where the additional index "SLR" specifies the uptake mechanism.

This expression captures both uptake due to reversible adsorption and desorption, as well as irreversible reactive uptake which is contained implicitly in the surface concentration. During irreversible uptake species $X_{i}(\mathrm{~s})$ reacts with the surface so that $\left[\mathrm{X}_{i}\right]_{\mathrm{S}}$ decreases, leading to a decrease in desorption flux.

For GSRs the effective uptake coefficient is determined entirely by chemical reactions, i.e. $J_{\text {net, } X_{i}}^{l}=L_{\mathrm{g}, \mathrm{ss}, \mathrm{X}_{i}}^{l}$ (chemical loss of gas species in reactions with the quasi-static surface layer, analogue to Eq. 15). It has to take into account that part of the reactive surface in the quasi-static surface layer is covered by species adsorbed in the sorption layer $\left(\theta_{\mathrm{s}}^{l}\right)$, and that only part of the quasi-static surface layer may actually be covered with the reactive substance $\mathrm{Y}_{j}\left(\theta_{\mathrm{ss}, \mathrm{Y}_{j}}^{l}\right)$ :

$\gamma_{\mathrm{GSR}, \mathrm{X}_{i}}^{\prime l}=\left(1-\theta_{\mathrm{s}}^{l}\right) \sum_{n=1}^{N_{\mathrm{GSR}}} \sum_{j=1}^{N_{\mathrm{nv}}} c_{\mathrm{GSR} n, \mathrm{~g}, \mathrm{X}_{i}} \gamma_{\mathrm{X}_{i}, \mathrm{Y}_{j}} \theta_{\mathrm{ss}, \mathrm{Y}_{j}}^{l}$
$=\left(1-\sum_{i=1}^{N_{\mathrm{v}}} \sigma_{\mathrm{X}_{i}}\left[\mathrm{X}_{i}\right]_{\mathrm{s}}^{l}\right) \sum_{n=1}^{N_{\mathrm{GSR}}} \sum_{j=1}^{N_{\mathrm{nv}}} c_{\mathrm{GSR} n, \mathrm{~g}, \mathrm{X}_{i}} \gamma_{\mathrm{X}_{i}, \mathrm{Y}_{j}} \sigma_{\mathrm{Y}_{j}}\left[\mathrm{Y}_{j}\right]_{\mathrm{ss}}^{l}$.

\section{Simulation parameters and assumptions}

We assume that the emitted diesel soot particles are coated with one monolayer of PAHs which we treat as a single species (termed PAH in the following). Clearly, this is a highly idealized assumption and it has to be kept in mind that atmospheric soot particles likely contain more than one monolayer of PAHs. Furthermore, we do not include the concurrent condensation of inorganic or secondary organic aerosol mass on the particles, i.e. in our simulations the PAHs and their oxidised derivatives stay on the surface and are not located within the particle bulk.

In our simulations, $\mathrm{O}_{3}(\mathrm{~g}), \mathrm{NO}_{2}(\mathrm{~g})$, and $\mathrm{H}_{2} \mathrm{O}(\mathrm{g})$ compete for adsorption on reactive surface sites. Subsequently, $\mathrm{O}_{3}(\mathrm{~s})$ and $\mathrm{NO}_{2}(\mathrm{~s})$ can undergo the surface layer reactions summarised in Table 2. $\mathrm{Y}_{j}\left(j=2, \ldots, N_{\mathrm{nv}}\right)$ are non-volatile oxidation and, possibly, nitration products of PAH whose exact chemical structure is not known (Springmann et al., 2009; Shiraiwa et al., 2009). $\mathrm{H}_{2} \mathrm{O}$ (s) does not react chemically in our scenarios. $\mathrm{OH}(\mathrm{g})$ and $\mathrm{NO}_{3}(\mathrm{~g})$ radicals are considered to undergo gas-surface reactions (Table 2).

\subsection{Physico-chemical parameters}

Particle-bound PAHs consist of three or more aromatic rings with a major mass fraction made up by three- to fivering compounds (Harner and Bidleman, 1998; El Haddad et al., 2009). As pyrene is one of the most widely reported molecules in soot studies (e.g., Pakbin et al., 2009; Kashiwakura and Sakamoto, 2010) and contributes a major fraction to the total PAH mass on the particles we use its values of molar mass $M$ and molecular cross section $\sigma$ as representative values for soot-bound PAHs: $M_{\mathrm{PAH}}=202.3 \times$ $10^{-3} \mathrm{~kg} \mathrm{~mol}^{-1}$ and $\sigma_{\mathrm{PAH}}=8 \times 10^{-15} \mathrm{~cm}^{2}$ representing four aromatic rings of $2 \times 10^{-15} \mathrm{~cm}^{2}$ (Shiraiwa et al., 2009).

Reaction rate coefficients and reactive uptake coefficients are summarised in Table 2. For the reaction of $\mathrm{O}_{3}$ with $\mathrm{PAH}$ (SLR1) we use a rate coefficient for benzo[ $a]$ pyrene that is based on the re-evaluation of a flow tube experiment (Pöschl et al., 2001; Shiraiwa et al., 2009). We assume the oxidation of secondary and tertiary species by $\mathrm{O}_{3}$ (SLR2 and SLR3) to proceed considerably slower than that of the primary PAHs (Ammann and Pöschl, 2007). The rate coefficient for the $\mathrm{NO}_{2}$ reaction with $\mathrm{Y}_{2}$ (SLR4) is based on flow tube and filter exposure experiments (Ammann and Pöschl, 2007), while that for the reaction with $\mathrm{Y}_{3}$ (SLR5) is taken from Springmann et al. (2009) who derived it from the results of flow 
reactor measurements by Ammann et al. (1998). It represents an upper limit estimation for the conditions considered here due to a smaller amount of soot surface per unit volume in the present study. For the surface layer reaction between $\mathrm{O}_{3}(\mathrm{~s})$ and $\mathrm{NO}_{2}$ (s) (SLR6) and the subsequent oxidation of PAH by $\mathrm{NO}_{3}$ (s) (SLR7) rate coefficients are chosen according to recommendations in Shiraiwa et al. (2009). We use reactive uptake coefficients for $\mathrm{OH}(\mathrm{g})$ and $\mathrm{NO}_{3}(\mathrm{~g})$ on pyrene from Bertram et al. (2001) and Gross and Bertram (2008), respectively.

Table 3 lists the values of accommodation coefficients, molecular cross sections, and desorption lifetimes used in the present study. They follow closely the choice of Shiraiwa et al. (2009), whereas the desorption life time of $\mathrm{H}_{2} \mathrm{O}$ has been changed to the average of all the values they listed. The apparent long desorption lifetime of $\mathrm{O}_{3}(10 \mathrm{~s})$ employed in this study includes the adsorption and decomposition of $\mathrm{O}_{3}$. Here, we opt to describe the oxidation of particle-bound PAHs by $\mathrm{O}_{3}$ with a simple Langmuir-Hinshelwood mechanism (Shiraiwa et al., 2009). Although, on a mechanistic level, this description is incomplete (Shiraiwa et al., 2011) it does not affect the overall particle surface oxidation and is less demanding in terms of computational power. Molecular cross sections for $\mathrm{O}_{3}, \mathrm{NO}_{2}$, and $\mathrm{H}_{2} \mathrm{O}$ are given by Pöschl et al. (2001) and Shiraiwa et al. (2009) $\left(\sigma_{\mathrm{O}_{3}}\right)$, Ammann and Pöschl (2007) $\left(\sigma_{\mathrm{NO}_{2}}\right)$, and Nishino (2001) $\left(\sigma_{\mathrm{H}_{2} \mathrm{O}}\right)$, respectively. Due to the lack of literature data the intermediate value of $1.7 \times 10^{-15} \mathrm{~cm}^{2}$ is also used for $\sigma_{\mathrm{NO}_{3}}$. Gas phase diffusion coefficients for $\mathrm{OH}$ and $\mathrm{NO}_{3}$ in air are taken from Ivanov et al. (2007) and Rudich et al. (1996), respectively.

\subsection{Scenario setups}

In our urban plume scenario we track a particle population in an air parcel that is advected over an urban polluted region. It is followed for $24 \mathrm{~h}$ starting at 06:00 a.m. Background trace gas concentrations used for initialization of the air parcel's gas phase composition are taken from Riemer et al. (2009). Environmental parameters are kept constant at $T=293 \mathrm{~K}$ and $p=1013.25 \mathrm{hPa}$. The soot particles in our model have spherical shape and are emitted with a lognormal size distribution $\left(d_{\mathrm{p}}=50 \mathrm{~nm}, \log \sigma=0.24\right)$ representative of diesel soot (Kittelson et al., 2006).

The particles are emitted at a "constant" rate (one Poisson sample at every time step, as described in Sect. 2.1 and Riemer et al. (2009)). The soot emission rate was chosen to yield a concentration of approximately $10 \mu \mathrm{g} \mathrm{m}^{-3}$ after $24 \mathrm{~h}$ when starting the simulation without any soot particles. This final value corresponds to urban polluted conditions (e.g., Seinfeld and Pandis, 2006). Note that we neglect removal processes here.

Concerning the gas phase we distinguish between scenarios with a high relative humidity $(\mathrm{RH})$ of $80 \%$ (scenarios $\mathrm{A}$ and $\mathrm{B}$, see Table 4) and a low RH of $30 \%$ (C and D, Table 4 ), i.e., $1.8 \times 10^{4} \mathrm{ppm}$ and $6.9 \times 10^{3} \mathrm{ppm}$ of water vapour
Table 4. Scenario definitions with respect to relative humidity (RH) and $\mathrm{NO}_{\mathrm{X}}$ emission levels.

\begin{tabular}{ccc}
\hline Scenario & $\mathrm{RH}$ & $\mathrm{NO}_{\mathrm{x}}$ emission level \\
\hline $\mathrm{A}$ & $80 \%$ & high \\
$\mathrm{B}$ & $80 \%$ & low \\
$\mathrm{C}$ & $30 \%$ & high \\
$\mathrm{D}$ & $30 \%$ & low \\
\hline
\end{tabular}

in the air, respectively. We consider different RH levels because Springmann et al. (2009) showed that competitive co-adsorption of $\mathrm{H}_{2} \mathrm{O}$ makes a profound difference in $\mathrm{PAH}$ degradation. The emission rates of trace gases are based on simulations of measurements during the Southern California Air Quality Study of 1987 (Zaveri et al., 2008). These emissions lead to a high $\left[\mathrm{NO}_{\mathrm{x}}\right]_{\mathrm{g}}$ regime. In order to also obtain a low $\left[\mathrm{NO}_{\mathrm{x}}\right]_{\mathrm{g}}$ scenario we multiply the $\mathrm{NO}$ and $\mathrm{NO}_{2}$ emission rates by 0.1 . This is done to examine the effects of different oxidant levels in general and also because simulations by Saathoff et al. (2001) for the two different photochemical regimes yielded considerably different results. Together, $\mathrm{RH}$ and $\mathrm{NO}_{\mathrm{x}}$ emission levels define the four scenarios $\mathrm{A}-\mathrm{D}$ as given in Table 4.

All simulations were started with about 300 particles to resolve the size distribution of soot particles in the air parcel. In order to reduce sampling errors caused by the finite number of simulated particles we repeated the simulations for each of the four scenarios (Table 4) at least eleven times and averaged over the ensemble for determination of populationrelated quantities.

We chose a time step of one minute for all our simulations. This is short enough to reasonably resolve heterogeneous chemical reactions except for one specific case. The GSR between $\mathrm{NO}_{3}$ and PAH (GSR2) proceeds extremely rapidly at high $\mathrm{NO}_{3}(\mathrm{~g})$ concentrations during the first time step of a particle's atmospheric lifetime (right after its emission). Hence, $[\mathrm{PAH}]_{\mathrm{ss}}$ is depleted very quickly. However, the much slower $\mathrm{PAH}-\mathrm{O}_{3}$ reaction (SLR1) that produces $\mathrm{Y}_{2}$ depends on the availability of PAH. Consequently, $\mathrm{Y}_{2}$ formation is overestimated if the initial $[\mathrm{PAH}]_{\mathrm{ss}}$ value is used for the entire first time step $\Delta t$. In order to avoid this error we introduced an approximation for $\mathrm{Y}_{2}$ formation during that time step:

$\left[\mathrm{Y}_{2}\right]_{\mathrm{SS}}^{l}(\Delta t)=\int_{0}^{\Delta t} k_{\mathrm{O}_{3}, \mathrm{PAH}} \cdot\left[\mathrm{O}_{3}\right]_{\mathrm{S}}^{l}(t) \cdot[\mathrm{PAH}]_{\mathrm{SS}}^{l}(t) d t$

Here, $\left[\mathrm{O}_{3}\right]_{\mathrm{s}}(t)$ and $[\mathrm{PAH}]_{\mathrm{ss}}(t)$ are parameterised as follows, based on the time evolution of these species that we obtained when using a smaller time step $\left(<10^{-3} \mathrm{~s}\right)$ :

$\left[\mathrm{O}_{3}\right]_{\mathrm{s}}^{l}(t)=\left[\mathrm{O}_{3}\right]_{\mathrm{s}, \Delta \mathrm{t}}^{l}\left(1-e^{-\lambda^{l} t}\right)$ 
$[\mathrm{PAH}]_{\mathrm{SS}}^{l}(t)=[\mathrm{PAH}]_{\mathrm{ss}, 0} e^{-\kappa^{l} t}$,

where $\left[\mathrm{O}_{3}\right]_{\mathrm{s}, \Delta \mathrm{t}}^{l}$ denotes $\mathrm{O}_{3}$ surface concentration after $\Delta t$ as determined by the steady state calculation (see below) and $[\mathrm{PAH}]_{\mathrm{ss}, 0}$ is the initial PAH surface concentration $\left(=\sigma_{\mathrm{PAH}}^{-1}\right)$. The parameters $\lambda^{l}$ and $\kappa^{l}$ are based on the fastest flux terms involved (adsorption and desorption of $\mathrm{O}_{3}$ and GSR2 itself):

$\lambda^{l}=\alpha_{\mathrm{s}, 0, \mathrm{O}_{3}}(1-\underbrace{\theta_{\mathrm{s}, 0}^{l}}_{=0}) \frac{\omega_{\mathrm{O}_{3}}}{4} \frac{\left[\mathrm{O}_{3}\right]_{\mathrm{g}}}{\left[\mathrm{O}_{3}\right]_{\mathrm{s}, \Delta \mathrm{t}}^{l}}-\frac{1}{\tau_{\mathrm{d}, \mathrm{O}_{3}}}$,

$\kappa^{l}=\gamma_{\mathrm{NO}_{3}, \mathrm{PAH}}\left(1-\theta_{\mathrm{s}, \Delta \mathrm{t}}^{l}\right) \underbrace{\theta_{\mathrm{ss}, \mathrm{PAH}, 0}^{l}}_{=1} \sigma_{\mathrm{PAH}} \frac{\omega_{\mathrm{NO}_{3}}}{4}\left[\mathrm{NO}_{3}\right]_{\mathrm{g}}$.

In these equations $\theta_{\mathrm{s}, 0}^{l}$ denotes coverage of the sorption layer of a fresh particle $(=0), \theta_{\mathrm{s}, \Delta \mathrm{t}}^{l}$ is the sorption layer coverage after the first time step of the particle's lifetime as calculated from the steady state equations (see below), and $\theta_{\mathrm{ss}, \mathrm{PAH}, 0}$ is the initial coverage of the quasi-static surface layer with PAH (=1). The integral (Eq. 18) is solved analytically in the model.

$\mathrm{O}_{3}(\mathrm{~s}), \mathrm{NO}_{2}(\mathrm{~s})$, and $\mathrm{H}_{2} \mathrm{O}(\mathrm{s})$ reach an equilibrium between adsorption and desorption quickly compared to the time scales of the chemical reactions. We therefore assume the sorption layer concentrations of adsorbing species to be in steady state:

$\frac{d\left[\mathrm{X}_{i}\right]_{\mathrm{s}}^{l}}{d t}=J_{\mathrm{ads}, \mathrm{X}_{i}}^{l}-J_{\mathrm{des}, \mathrm{X}_{i}}^{l}-L_{\mathrm{s}, \mathrm{s}, \mathrm{X}_{i}}^{l}-L_{\mathrm{s}, \mathrm{ss}, \mathrm{X}_{i}}^{l}=0$,

where $\mathrm{X}_{i}=\mathrm{O}_{3}(\mathrm{~s}), \mathrm{NO}_{2}(\mathrm{~s}), \mathrm{H}_{2} \mathrm{O}(\mathrm{s})$.

Additionally, $\mathrm{NO}_{3}(\mathrm{~s})$ production, desorption, and chemical loss equilibrate quickly compared to the time scales on which quasi-static surface layer species concentrations ([Y $\left.\left.{ }_{j}\right]_{\mathrm{ss}}\right)$ change so that we can also assume steady state for $\left[\mathrm{NO}_{3}\right]_{\mathrm{s}}$ :

$\frac{d\left[\mathrm{NO}_{3}\right]_{\mathrm{s}}^{l}}{d t}=P_{\mathrm{s}, \mathrm{s}, \mathrm{NO}_{3}}^{l}-J_{\mathrm{des}, \mathrm{NO}_{3}}^{l}-L_{\mathrm{s}, \mathrm{ss}, \mathrm{NO}_{3}}^{l}=0$.

\section{Results and discussion}

\subsection{Gas phase}

The evolution of gas phase oxidant concentrations that drive heterogeneous chemistry in our simulations is shown in Fig. 2 for scenarios A and D. $\left[\mathrm{O}_{3}\right]_{\mathrm{g}}$ shows the typical behaviour for polluted conditions (e.g., Finlayson-Pitts and Pitts, 2000; Seinfeld and Pandis, 2006; Khoder, 2009), an increase during morning hours followed by a peak in the afternoon and subsequent decline until the cycle starts anew. $\mathrm{OH}(\mathrm{g})$ and $\mathrm{NO}_{3}(\mathrm{~g})$ are only present in significant amounts during the day or night, respectively. Different water vapour concentrations have a negligible influence on gas phase evolution compared to the effect of different $\mathrm{NO}_{\mathrm{x}}$ emission levels. Hence, oxidant concentrations are very similar in scenarios $\mathrm{A}$ and $\mathrm{C}$, as well as in scenarios $\mathrm{B}$ and $\mathrm{D}$. The main

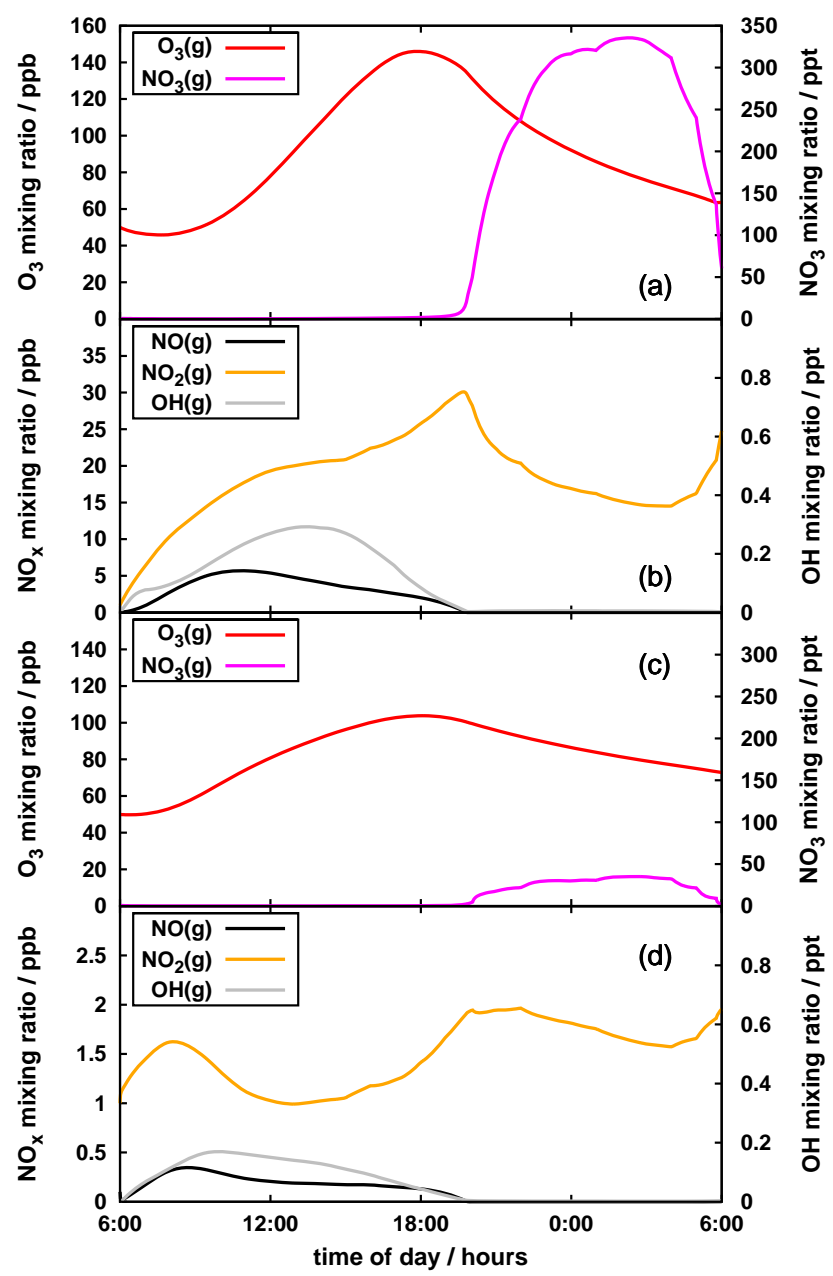

Fig. 2. Evolution of gas concentrations in an urban polluted environment during the simulated $24 \mathrm{~h}$ period. Panel (a) and (b) represent scenario A with high water vapour concentration and high $\mathrm{NO}_{\mathrm{x}}$ emissions. Panel (c) and (d) represent scenario D with low water vapour concentration and low $\mathrm{NO}_{\mathrm{x}}$ emissions. Note the different scales on the vertical axes.

differences between the gas phases of scenarios with high and low $\mathrm{NO}_{\mathrm{x}}$ emissions are in $\mathrm{NO}_{\mathrm{x}}$ and $\mathrm{NO}_{3}$ concentrations, as well as in peak $\left[\mathrm{O}_{3}\right]_{\mathrm{g}}$ levels which are all higher in the high $\mathrm{NO}_{\mathrm{x}}$ emission scenarios.

Overall, our scenarios represent polluted conditions with elevated $\mathrm{O}_{3}$ concentrations. $\mathrm{NO}_{\mathrm{x}}$ levels do not reach extreme values but are also clearly higher than under background conditions. Concentrations of $\mathrm{OH}$ and $\mathrm{NO}_{3}(\mathrm{~g})$ are on the same order of magnitude as known from atmospheric measurements (e.g., Finlayson-Pitts and Pitts, 2000; Emmerson et al., 2005; Seinfeld and Pandis, 2006; Dusanter et al., 2009, and references therein). 

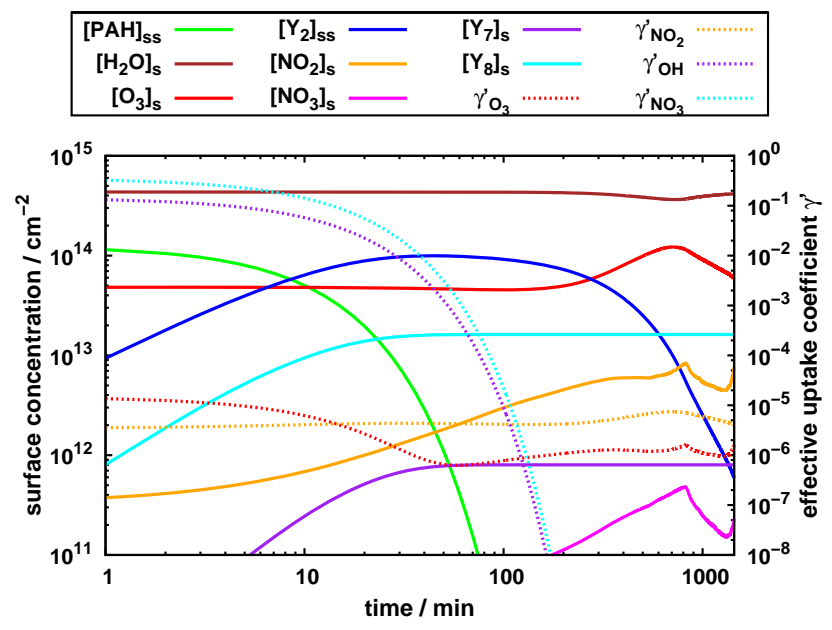

Fig. 3. Evolution of surface species concentrations and effective uptake coefficients during the simulated $24 \mathrm{~h}$ period on an individual particle emitted at 06:00 a.m. in scenario A. Note the logarithmic time axis.

\subsection{Individual particles}

As an example for the evolution of particle surface composition, Fig. 3 shows a particle emitted at 06:00 a.m. in scenario A (high $\mathrm{RH}$ and high $\mathrm{NO}_{\mathrm{x}}$ emissions). For this particle, $[\mathrm{PAH}]_{\mathrm{ss}}$ declines to half its initial value within approximately eight minutes. In this case PAH degradation is mainly due to the oxidation by adsorbed $\mathrm{O}_{3}$, which can be deduced from the concentrations of the different oxidation products: $\mathrm{Y}_{2}$, the product of the $\mathrm{PAH}-\mathrm{O}_{3}$ reaction (SLR1) reaches a much higher concentration than the products of the $\mathrm{PAH}-\mathrm{OH}$ (GSR1) and $\mathrm{PAH}-\mathrm{NO}_{3}(\mathrm{GSR} 2)$ reactions, $\mathrm{Y}_{7}$ and $\mathrm{Y}_{8}$, respectively.

One can also clearly see that $\left[\mathrm{O}_{3}\right]_{\mathrm{s}}$ and $\left[\mathrm{NO}_{2}\right]_{\mathrm{s}}$ follow the corresponding gas phase concentrations. This is due to changes in the relative amounts of $\mathrm{O}_{3}(\mathrm{~g})$ and $\mathrm{NO}_{2}(\mathrm{~g})$ to $\left[\mathrm{H}_{2} \mathrm{O}\right]_{\mathrm{g}}$ (=const.) during the simulation period. Thus, adsorption rates change accordingly, leading to corresponding changes in surface concentrations.

Effective uptake coeffcients for $\mathrm{O}_{3}$ and $\mathrm{NO}_{2}$ are initially equal to the respective accommodation coefficients $\left(\alpha_{\mathrm{s}, 0, \mathrm{O}_{3}}\right.$ and $\left.\alpha_{\mathrm{s}, 0, \mathrm{NO}_{2}}\right)$, but decline by several orders of magnitude during the first minute of the particle's atmospheric lifetime (not shown). After the first minute, an equilibrium between reversible adsorption and desorption is established. Thus, in Fig. 3, $\gamma_{\mathrm{O}_{3}}^{\prime}$ and $\gamma_{\mathrm{NO}_{2}}^{\prime}$ always follow the concentrations of the gases' major surface reaction partners, e.g. $\gamma_{\mathrm{O}_{3}}^{\prime}$ first follows $[\mathrm{PAH}]_{\mathrm{ss}}$ and later on $\left[\mathrm{NO}_{2}\right]_{\mathrm{s}}$, when SLR6 takes over from SLR1 as the major sink of $\mathrm{O}_{3}(\mathrm{~s}) \cdot \gamma_{\mathrm{OH}}^{\prime}$ and $\gamma_{\mathrm{NO}_{3}}^{\prime}$ closely follow $[\mathrm{PAH}]_{\mathrm{ss}}$ since the GSRs with PAH are the only sinks for $\mathrm{OH}$ and $\mathrm{NO}_{3}$ on the surface.
The effect of lowering RH from $80 \%$ to $30 \%$ on the particle shown in Fig. 3 is a reduction of $\left[\mathrm{H}_{2} \mathrm{O}\right]_{\mathrm{s}}$ by $47 \%$ on average over the simulation time. Correspondingly, both $\left[\mathrm{O}_{3}\right]_{\mathrm{s}}$ and $\left[\mathrm{NO}_{2}\right]_{\mathrm{s}}$ increase by about $17 \%$ and $71 \%$, respectively, due to more available sorption sites. This leads to higher surface reaction rates so that effective uptake coefficients for $\mathrm{O}_{3}$ and $\mathrm{NO}_{2}$ increase by factors of 2.3 and 1.6, respectively. $\gamma_{\mathrm{OH}}^{\prime}$ and $\gamma_{\mathrm{NO}_{3}}^{\prime}$ are initially higher in the low $\mathrm{RH}$ scenarios because less of the sorption layer is covered by adsorbed molecules and are lower later on because PAH is depleted more quickly. Note that the numbers given in this paragraph depend strongly on gas phase composition at the time of the particle's emission and also on particle size.

Qualitatively, these results are in agreement with modelling studies by Springmann et al. (2009) and Shiraiwa et al. (2009). Absolute values, however, differ quite strongly because Shiraiwa et al. (2009) did not consider changes in gas phase composition, while Springmann et al. (2009) simulated fewer heterogeneous reactions and used different values for some of the physico-chemical parameters.

\subsection{Population PAH half-life}

The PAH(ss) half-life $\tau_{1 / 2}$, averaged over the whole particle population, closely mirrors the gas phase evolution of the major oxidant as can be seen from Fig. 4. Thus, during the day, $\tau_{1 / 2}$ is highest when $\left[\mathrm{O}_{3}\right]_{\mathrm{g}}$ reaches its local minimum, while at night $\tau_{1 / 2}$ attains very low values due to high $\mathrm{NO}_{3}(\mathrm{~g})$ concentrations. During that time, the GSR of $\mathrm{NO}_{3}$ and PAH is extremely efficient in degrading PAH, so that $\tau_{1 / 2}$ can decrease to only a few seconds during the night. However, the time resolution of one minute employed in our simulations does not permit the determination of half-lives shorter than one minute. A similarly short lifetime at elevated $\mathrm{NO}_{3}(\mathrm{~g})$ concentrations has also been observed in a modeling study by Shiraiwa et al. (2009).

Co-adsorption of water vapour prolongs the PAH half-life by up to three minutes (not shown), i.e. about $50 \%$, during daytime oxidation when comparing the $80 \%-\mathrm{RH}$ scenarios (A and $\mathrm{B}$ ) to the corresponding 30\%-RH scenarios ( $\mathrm{C}$ and D). During the night, the PAH half-life is up to $100 \%$ longer at high $\mathrm{RH}$ than at low $\mathrm{RH}$. The relative increase may be even greater during the period of peak $\mathrm{NO}_{3}(\mathrm{~g})$ concentrations where the time resolution of one minute does not allow us to calculate it accurately.

Longer half-lives in response to higher water vapour concentrations in the atmosphere were also observed by Springmann et al. (2009) and can be explained by the large fraction of active surface sites that is covered by $\mathrm{H}_{2} \mathrm{O}$ molecules and thus unavailable for chemical reactions. Hence, in the high RH scenarios, less PAH is oxidised per unit time.

We did not consider condensation of water vapour (note that condensation is fundamentally different from the adsorption of a monolayer of water molecules) or semivolatile substances, such as $\mathrm{HNO}_{3}$ and $\mathrm{H}_{2} \mathrm{SO}_{4}$, on the particles. If 


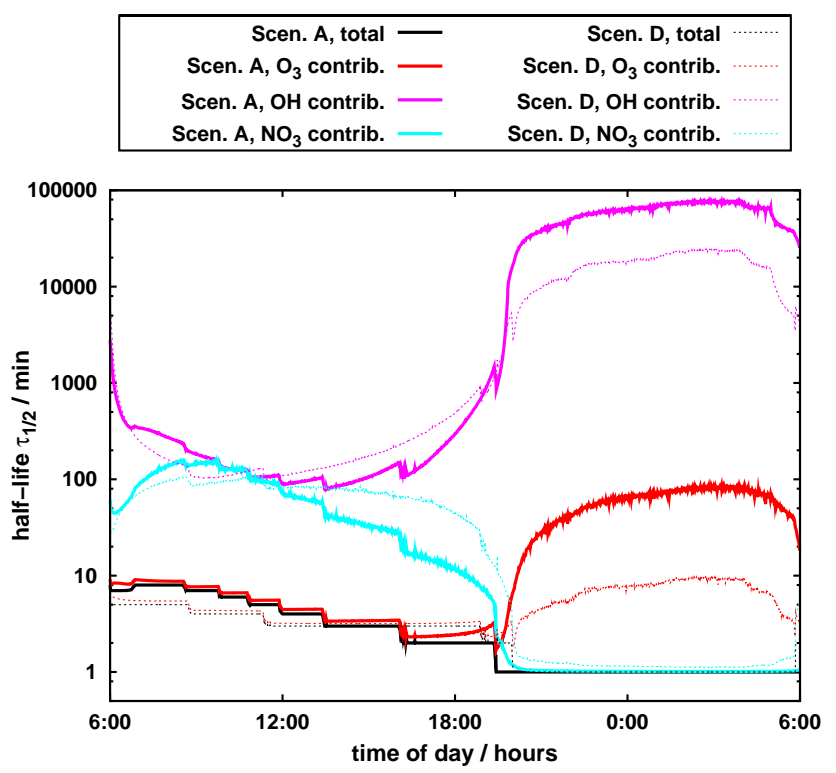

Fig. 4. Evolution of PAH half-life on soot particles in an urban polluted environment during the simulated $24 \mathrm{~h}$ period (thick, solid lines: scenario A; thin, dotted lines: scenario D). Colored lines show individual contributions to $\mathrm{PAH}(\mathrm{ss})$ degradation by $\mathrm{O}_{3}, \mathrm{OH}$, and $\mathrm{NO}_{3}$ and indicate half-lives calculated according to the observed rates of SLR1, GSR1, and GSR2 under the assumption for each of the gases that it was the only reacting oxidant.

condensation proceeds on similar or shorter time scales than the heterogeneous oxidation, $\mathrm{PAH}$ (ss) degradation may be delayed considerably. It might also be slowed down if multilayer coating was considered because only the outermost layer would be directly exposed to reactive gas species. On the other hand, photolysis of particle-bound PAHs may lead to enhanced degradation (Vione et al., 2004).

The individual oxidants' contributions to PAH(ss) degradation shown in Fig. 4 were computed based on the observed rates of reactions SLR1 $\left(\mathrm{O}_{3}-\mathrm{PAH}\right), \mathrm{GSR} 1(\mathrm{OH}-\mathrm{PAH})$, and GSR2 $\left(\mathrm{NO}_{3}-\mathrm{PAH}\right)$. If these reactions proceeded at the same rates, but without the other oxidants reacting with the surface, they would lead to the half-lives shown in Fig. 4.

It might come as a surprise that $\mathrm{OH}$ has a negligible effect on the oxidation of particle-bound $\mathrm{PAH}$ despite its high reactivity. However, due to its extremely low concentration even at peak values, its collision flux with particles is also very small. As an example, consider a particle of diameter $d_{\mathrm{p}}=50 \mathrm{~nm}$ with about half of its sorption layer covered by adsorbing gases. One can calculate pseudo-first order PAH loss rate constants $k^{\prime}$ for the three reactions SLR1, GSR1, and GSR2 on such a particle:

$k_{\mathrm{O}_{3}, \mathrm{PAH}}^{\prime}=2.2 \times 10^{-3} \mathrm{~s}^{-1}$,

$k_{\mathrm{OH}, \mathrm{PAH}}^{\prime}=2.4 \times 10^{-4} \mathrm{~s}^{-1}$,
$k_{\mathrm{NO}_{3}, \mathrm{PAH}}^{\prime}=7.0 \times 10^{-1} \mathrm{~s}^{-1}$.

For these calculations, we assumed concentrations of $\left[\mathrm{O}_{3}\right]_{\mathrm{s}}=8 \times 10^{13} \mathrm{~cm}^{-2}, \quad[\mathrm{OH}]_{\mathrm{g}}=6 \times 10^{6} \mathrm{~cm}^{-3}$ (corresponding to peak values observed in our simulations), and $\left[\mathrm{NO}_{3}\right]_{\mathrm{g}}=300 \mathrm{ppt}$. These rates show that, even at peak $[\mathrm{OH}]_{\mathrm{g}}$, its contribution to PAH depletion is at most about $10 \%$ of that of $\mathrm{O}_{3}$, whereas oxidation by $\mathrm{NO}_{3}(\mathrm{~g})$ is extremely efficient at high nighttime concentrations. Compared to the benzo[ $a]$ pyrene half-lives on soot particles found by Springmann et al. (2009) and Pöschl et al. (2001), which were on the order of tens of minutes, the PAH half-lives reported here are shorter, especially during the night. The discrepancy is mainly due to $\mathrm{PAH}(\mathrm{ss})$ oxidation by $\mathrm{NO}_{3}(\mathrm{~g})$ which neither Pöschl et al. (2001) nor Springmann et al. (2009) considered, but which was also observed in a recent study by Shiraiwa et al. (2009) that included oxidation by $\mathrm{NO}_{3}$. This explanation is supported by the work of Gross and Bertram (2008) who calculated atmospheric PAH(ss) lifetimes on the order of tens of seconds for solid pyrene exposed to $50 \mathrm{ppt}$ of $\mathrm{NO}_{3}(\mathrm{~g})$. Furthermore, gas phase $\mathrm{O}_{3}$ concentrations differ between our simulations and the studies mentioned above.

\subsection{Effective population uptake coefficients}

We define the effective population uptake coefficient $\overline{\gamma^{\prime}} \mathrm{x}_{i}$ as the surface area-weighted average over the whole population of soot particles which, at a given time, may be photochemically aged to different degrees:

$\overline{\gamma^{\prime} \mathrm{X}_{i}}=\frac{\sum_{l=1}^{N_{\mathrm{p}}} S^{l} \gamma_{\mathrm{X}_{i}}^{\prime l}}{\sum_{l=1}^{N_{\mathrm{p}}} S^{l}}$.

Here, $S^{l}$ is the surface area of particle $l$ and $\gamma_{\mathrm{X}_{i}}^{\prime l}$ the effective uptake coefficient for species $\mathrm{X}_{i}$ on that particle. Multiplied with the collision flux $J_{\text {coll, } X_{i}}^{l}$ (Eq. 7) and the soot particles' surface area per unit volume, effective population uptake coefficients yield the net removal rate of a reactive gas from the gas phase.

Equation (28) is evaluated for $\mathrm{O}_{3}, \mathrm{NO}_{2}, \mathrm{NO}_{3}$, and $\mathrm{OH}$, and the results are shown in Fig. 5 for scenarios $\mathrm{A}$ and $\mathrm{D}\left(\overline{\gamma^{\prime}} \mathrm{OH}\right.$ and $\overline{\gamma^{\prime}} \mathrm{NO}_{3}$ were smoothed using a moving average over 20 consecutive time steps). $\overline{\gamma^{\prime}} \mathrm{O}_{3}$ and $\overline{\gamma^{\prime}} \mathrm{NO}_{2}$ decline rapidly as already observed on the individual particle of Sect. 4.2 (note that effective uptake coefficients are initially equal to the corresponding accommodation coefficients for adsorbate-free surfaces $\alpha_{\mathrm{s}, 0, \mathrm{X}_{i}}$ ). The particle population is quickly dominated by aged particles that have relatively constant effective uptake coefficients for $\mathrm{O}_{3}$ and $\mathrm{NO}_{2}$ determined by SLR6. Thus, $\overline{\gamma^{\prime}} \mathrm{O}_{3}$ and $\overline{\gamma^{\prime}} \mathrm{NO}_{2}$ are also relatively constant throughout most of the simulated period. $\overline{\gamma^{\prime}} \mathrm{NO}_{3}$ and $\overline{\gamma^{\prime}}$ OH are determined entirely by degradation of PAH and differ only by the factor between their elementary reaction probabilities (see Eq. (18) and Table 2). The faster PAH is depleted, the lower the effective uptake coefficients for $\mathrm{NO}_{3}$ and $\mathrm{OH}$ become. This 


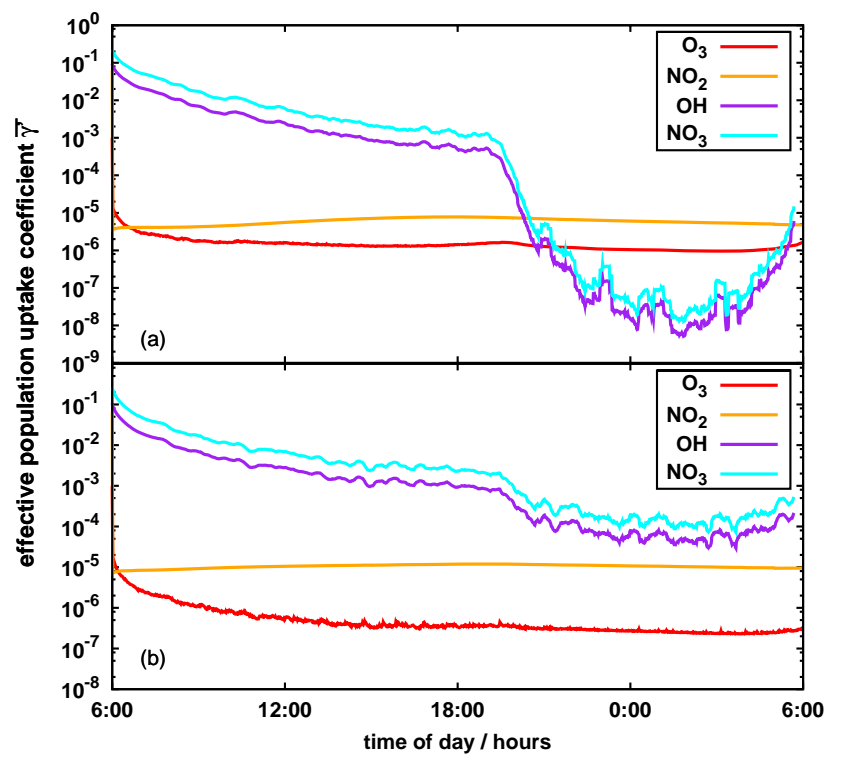

Fig. 5. Evolution of effective uptake coefficients averaged over the whole particle population at each time step during the simulated $24 \mathrm{~h}$ period. Panels (a) and (b) represent scenarios A and D, respectively.

is especially evident in the very low $\overline{\gamma^{\prime}} \mathrm{NO}_{3}$ and $\overline{\gamma^{\prime}}$ OH values during the night in the high $\mathrm{NO}_{\mathrm{x}}$ emission scenario $\mathrm{A}$.

Decreasing $\mathrm{RH}$ from $80 \%$ to $30 \%$ leads to an increase of effective population uptake coefficients for $\mathrm{O}_{3}$ and $\mathrm{NO}_{2}$. Averaged over the simulation time we find factors of up to approximately two between their values at low RH and at high $\mathrm{RH}$. This effect is most pronounced for $\overline{\gamma^{\prime}} \mathrm{O}_{3}$ in the high $\mathrm{NO}_{\mathrm{x}}$ emission scenarios (A and C). As described in Sect. 4.2 the increase is due to greater reaction rates of the adsorbing gases with PAH and a correspondingly larger net removal of these species from the gas phase. For $\overline{\gamma^{\prime}} \mathrm{OH}_{\text {and }} \overline{\gamma^{\prime}} \mathrm{NO}_{3}$ no general statement can be made. The effect depends on the interplay between less coverage of the sorption layer leading to less blocking of reactive sites on the one hand and less PAH available due to faster degradation by increased SLR rates on the other hand.

Our results support the assumption of a constant effective uptake coefficient for $\mathrm{O}_{3}$ that is often made in large-scale models (e.g., Bey et al., 2001; Tie et al., 2001; Matthias et al., 2009). However, since such models commonly use initial uptake coefficients - which are significantly higher than average effective uptake coefficients - such models may overestimate the effects of heterogeneous chemistry on soot particles, e.g. on oxidant concentrations. A reasonable value for $\overline{\gamma^{\prime}} \mathrm{O}_{3}$ for particles of different photochemical ages in an urban polluted environment would have to lie between $\sim 2 \times 10^{-7}$ and $\sim 2 \times 10^{-6}$ according to our findings. For $\overline{\gamma^{\prime}} \mathrm{NO}_{2}$, a constant value of $5 \times 10^{-6}$ to $10^{-5}$ appears to be a good ap- proximation. In the case of $\mathrm{OH}$ and $\mathrm{NO}_{3}$ the recommendation of a representative constant value would require detailed information about the system in question.

\subsection{Feedback on the gas phase}

In line with the rather low effective uptake coefficients that we find, feedback on the gas phase in terms of reduction of oxidant concentrations is negligible in our simulations. A possible reason why our results disagree with several other studies that found considerable reductions in $\left[\mathrm{O}_{3}\right]_{\mathrm{g}}$ (e.g., Aklilu and Michelangeli, 2004; Springmann et al., 2009) may be the amount of soot surface per unit volume of air. Our particle size distribution yields a value of $\sim 30 \mathrm{~m}^{2} \mathrm{~g}^{-1}$. Compared to laboratory measurements of ambient soot particles this is a realisitic value (Smekens et al., 2005). However, Springmann et al., for instance, used an upper limit estimation of $500 \mathrm{~m}^{2} \mathrm{~g}^{-1}$ for their simulations while Aklilu and Michelangeli reported only small effects for $46 \mathrm{~m}^{2} \mathrm{~g}^{-1}$ and it was their simulation with $218 \mathrm{~m}^{2} \mathrm{~g}^{-1}$ that yielded a significant feedback of heterogeneous reactions on the gas phase.

Reactions SLR5 and SLR6 ( $\mathrm{HONO}(\mathrm{g})$ and $\mathrm{NO}_{3}$ (s) formation) and subsequent desorption of the volatile products also do not significantly alter gas phase chemistry due to very low product yields. The finding that soot particles do not act as a significant source of HONO confirms the results of studies by Kleffmann et al. (1999), Arens et al. (2001), Aubin and Abbatt (2007), Springmann et al. (2009), and Nguyen et al. (2009) but disagrees with others (Ammann et al., 1998; Gerecke et al., 1998; Kotamarthi et al., 2001). It seems that the HONO production by reaction of $\mathrm{NO}_{2}$ with or on soot strongly depends on the type of soot and the associated physico-chemical parameters.

Sensitivity studies with different soot emission rates did not show any significant changes in feedback on the gas phase either. Since PAH half-life and effective uptake coefficients are determined by the available gas concentrations alone, these parameters were also insensitive to varying soot emission rates.

Possibly, uptake of $\mathrm{OH}$ and $\mathrm{NO}_{3}$ was underestimated because these species will most likely also react with secondary species on the soot surface. If such reactions proceeded at similar rates as those with the primary PAHs the influence on the radicals' gas phase concentrations may actually be more pronounced. The assumption of similar rates for oxidation of secondary species may be supported by a study of the $\mathrm{HO}_{2}$ reaction with soot by Bedjanian et al. (2005). They found no significant dependence of this reaction on particle age, which is related to the degree of oxidation. In contrast, if particle deposition or condensation of other atmospheric species onto soot lead to a decrease in the efficiency of heterogeneous removal of gas phase species, an even smaller feedback would be the result. 


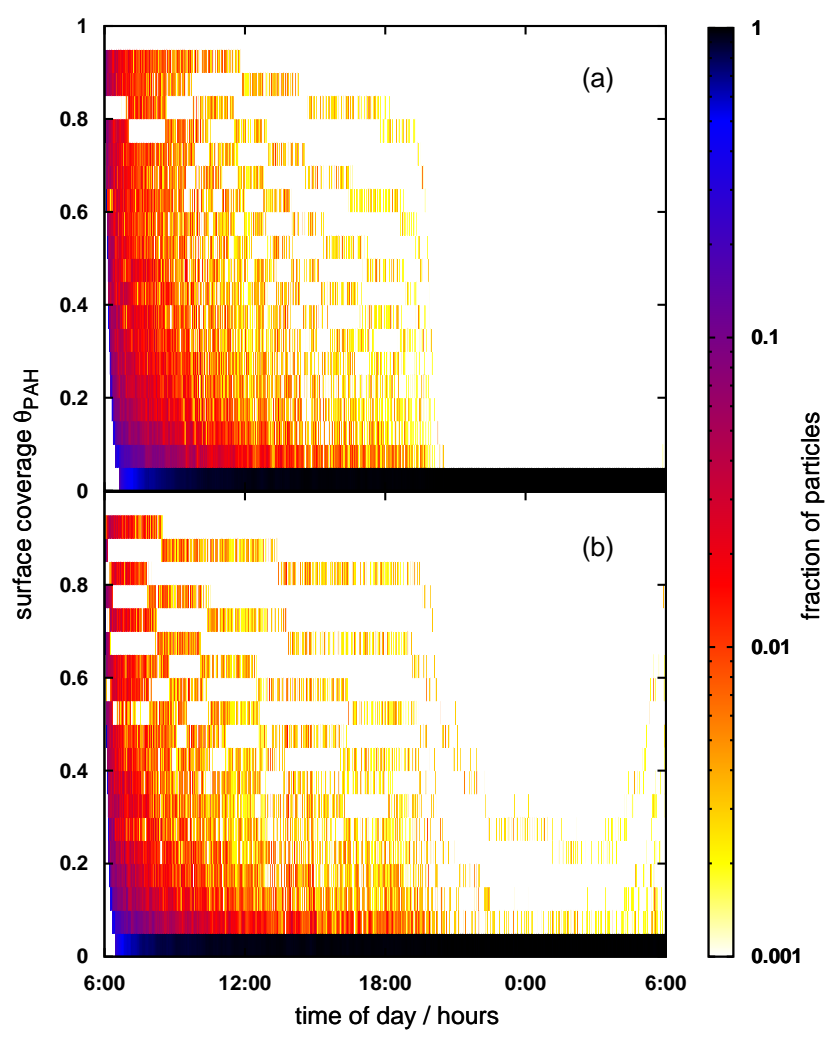

Fig. 6. Particle PAH surface coverage during the simulated $24 \mathrm{~h}$ period, averaged over the whole particle population. Panels (a) and (b) represent scenarios A and D, respectively. Fractional PAH surface coverage is plotted on the vertical axis in bins of width 0.05 and color coding gives the fraction of particles in the population with the corresponding coverage.

\subsection{PAH surface coverage}

At any time during the simulation, particles of different ages co-exist and contribute to the population-averaged quantities discussed above. To illustrate this, Fig. 6 shows the fraction of particles with a specific PAH surface coverage at each time step. It is evident that the population is dominated by aged particles with a PAH surface coverage of 0.05 or less because of the relatively short PAH half-life. During the night, fresh particles reach PAH coverage values of less than 0.05 within the first minute or two of their atmospheric lifetime due to the rapid oxidation by $\mathrm{NO}_{3}(\mathrm{~g})$. The slower PAH(ss) degradation during the $\left[\mathrm{O}_{3}\right]_{\mathrm{g}}$ minimum in the morning of the high $\mathrm{NO}_{\mathrm{x}}$ scenario A can also be seen in the upper panel of Fig. 6: the fraction of particles with surface coverage $>0.5$ is significantly higher during that time than in the lower panel which represents the low $\mathrm{NO}_{\mathrm{x}}$ scenario $\mathrm{D}$ which does not show this pronounced $\left[\mathrm{O}_{3}\right]_{\mathrm{g}}$ minimum. Similarly, in Fig. $6 \mathrm{~b}$ there is still a fraction of particles with surface coverages $>0.05$ during the night which indicates slower night time $\mathrm{PAH}(\mathrm{ss})$ degradation than in the high $\mathrm{NO}_{\mathrm{x}}$ scenarios as de- scribed in the previous sections. PAH surface coverage is slightly higher in high RH scenarios (A and B) than in low $\mathrm{RH}$ scenarios (C and $\mathrm{D}$ ) because of the slower PAH degradation (not shown).

\section{Summary and conclusions}

We extended the aerosol model PartMC-MOSAIC by incorporation of the PRA framework for heterogeneous kinetics. This allowed us for the first time to track the chemical composition of each individual particle in an ensemble of $\mathrm{PAH}-$ coated soot particles. Thus, particles of a continuous range of chemical ages could simultaneously be modelled within an urban polluted atmosphere with high concentrations of $\mathrm{O}_{3}$ and $\mathrm{NO}_{\mathrm{x}}$ as well as high soot particle emissions. Interactions of the particles with four major atmospheric oxidants $\left(\mathrm{O}_{3}\right.$, $\mathrm{NO}_{2}, \mathrm{OH}, \mathrm{NO}_{3}$ ) and the competitive co-adsorption of water vapour were studied. The underlying physical and chemical parameters represent the state of current research and are based on a compilation of relevant literature data.

In the simulations presented here, the PAH monolayer was oxidised within time scales of seconds to minutes. During the night, $\mathrm{NO}_{3}(\mathrm{~g})$ was found to deplete $\mathrm{PAH}(\mathrm{ss})$ rapidly by a gas-surface reaction. The potential importance of such a reaction for nitro-PAH formation was also indicated by field observations in a study by Reisen and Arey (2005). During the day, PAH(ss) half-lives were longer and mainly determined by a Langmuir-Hinshelwood type reaction with $\mathrm{O}_{3}$. For the investigated particle-environment system it was found that $\mathrm{OH}$ did not have a significant effect on $\mathrm{PAH}$ (ss) lifetime and thus on its chemical transformation. A change of $\mathrm{RH}$ from $30 \%$ to $80 \%$ lead to longer PAH half-lives by up to $50 \%$ at their peak during daytime and by up to $100 \%$ or possibly more at the low nighttime values.

When comparing the above results to field measurements, it has to be kept in mind that PAHs are not only found in the surface layer but also in the particle bulk which significantly increases their atmospheric lifetime since those PAHs may not be readily accessible for oxidation.

The exact structure of oxidised PAH reaction products has yet to be determined so that we cannot make predictions concerning toxicity based on our results. A study by Durant et al. (1996) indicated that oxygenation of PAHs may reduce their mutagenicity, but then again, nitration may lead to increased mutagenicity (Finlayson-Pitts and Pitts, 2000; Reisen and Arey, 2005). Nevertheless, as higher oxidation was shown to be well correlated with higher hygroscopicity (Jimenez et al., 2009; Liu et al., 2010), the conclusion seems justified that soot particles could quickly become efficient cloud condensation and, possibly, ice nuclei (Knopf et al., 2010, and references therein). The hydroperoxy radical $\left(\mathrm{HO}_{2}\right)$ may enhance heterogeneous PAH oxidation even further since it is also among the most reactive oxidants in the atmosphere and available at higher concentrations than 
$\mathrm{OH}$. However, literature on its reaction with soot or sootbound PAHs is limited (Saathoff et al., 2001; Bedjanian et al., 2005).

Effective uptake coefficients, averaged over the whole population of particles aged photochemically to different degrees, were found to be relatively constant over time for $\mathrm{O}_{3}$ $\left(\overline{\gamma^{\prime}} \mathrm{O}_{3} \sim 2 \times 10^{-7}\right.$ to $\left.\sim 2 \times 10^{-6}\right)$ and $\mathrm{NO}_{2}\left(\overline{\gamma^{\prime}} \mathrm{NO}_{2} \sim 5 \times 10^{-6}\right.$ to $\sim 10^{-5}$ ) in the four scenarios considered here, while $\overline{\gamma^{\prime}}$ OH and $\overline{\gamma^{\prime}} \mathrm{NO}_{3}$ strongly depended on the evolution of $[\mathrm{PAH}]_{\mathrm{ss}}$. The influence of different RH levels on the latter coefficients varied over time because it depends on the balance between more accessible PAH due to a smaller coverage of the sorption layer and less available PAH due to faster depletion by adsorbed reactive gases. ${\overline{\gamma^{\prime}}}_{\mathrm{O}_{3}}$ and ${\overline{\gamma^{\prime}}}_{\mathrm{NO}_{2}}$ were both higher in the $30 \% \mathrm{RH}$ scenarios (C and D) than in the $80 \% \mathrm{RH}$ scenarios (A and B), but differed only by factors of up to approximately two. In general, the low effective uptake coefficients found in this study suggest that it may not be necessary to consider soot particles as a sink for the corresponding trace gases in large-scale models. If consideration of heterogeneous chemistry on soot is desired in such models parameterisations of effective uptake coefficients and half-lives of particle surface-bound PAHs based on our results can be used as a good approximation to save computing time and power.

We did not find a measurable feedback of heterogeneous chemical reactions on soot on atmospheric gas phase composition. Neither were trace gas concentrations significantly reduced by consumption of the corresponding species on particle surfaces, nor were they increased by heterogeneous production and subsequent desorption from the particles.

All the above results are based on the assumptions that only a single PAH monolayer initially exists on the surface of an unreactive substrate and that the oxidation products remain on the particle surface. To account for PAHs and oxidative processes in multiple layers as well as in the particle bulk, a multilayer model (e.g., Shiraiwa et al., 2010) has to be applied. If a particle consists of multiple layers of PAHs and the volatilization of organic material occurs as observed for other organic substrates (Molina et al., 2004; Knopf et al., 2006; Kroll et al., 2011), this can significantly affect PAH degradation processes since PAHs from lower layers could be exposed to atmospheric oxidants upon such reactions.

Future research should account for a possible multilayer coating of soot particles with PAHs and for multistep Langmuir-Hinshelwood type reactions (Shiraiwa et al., 2009, 2011). Furthermore, physical processes such as deposition, coagulation, and condensation of semi-volatile species implemented in PartMC-MOSAIC should be enabled to assess the relative effects of chemical and physical aging of soot particles.

Acknowledgements. We gratefully acknowledge support from the National Science Foundation (ATM-0846255).

Edited by: M. Ammann

\section{References}

Aklilu, Y. A. and Michelangeli, D. V.: Box model investigation of the effect of soot particles on ozone downwind from an urban area through heterogeneous reactions, Environ. Sci. Technol., 38, 5540-5547, doi:10.1021/es035079x, 2004.

Ammann, M. and Pöschl, U.: Kinetic model framework for aerosol and cloud surface chemistry and gas-particle interactions - Part 2: Exemplary practical applications and numerical simulations, Atmos. Chem. Phys., 7, 6025-6045, doi:10.5194/acp-7-60252007, 2007.

Ammann, M., Kalberer, M., Jost, D. T., Tobler, L., Rossler, E., Piguet, D., Gaggeler, H. W., and Baltensperger, U.: Heterogeneous production of nitrous acid on soot in polluted air masses, Nature, 395, 157-160, 1998.

Arens, F., Gutzwiller, L., Baltensperger, U., Gaggeler, H. W., and Ammann, M.: Heterogeneous reaction of $\mathrm{NO}_{2}$ on diesel soot particles, Environ. Sci. Technol., 35, 2191-2199, 2001.

Arens, F., Gutzwiller, L., Gaggeler, H., and Ammann, M.: The reaction of $\mathrm{NO}_{2}$ with solid anthrarobin (1,2,10-trihydroxyanthracene), Phys. Chem. Chem. Phys., 4, 3684-3690, doi:10.1039/b201713j, 2002.

Aubin, D. G. and Abbatt, J. P. D.: Interaction of $\mathrm{NO}_{2}$ with hydrocarbon soot: Focus on HONO yield, surface modification, and mechanism, J. Phys. Chem. A, 111, 6263-6273, doi:10.1021/jp068884h, 2007

Bedjanian, Y., Lelièvre, S., and Le Bras, G.: Experimental study of the interaction of $\mathrm{HO}_{2}$ radicals with soot surface, Phys. Chem. Chem. Phys., 7, 334-341, doi:10.1039/b414217a, 2005.

Bernstein, J. A., Alexis, N., Barnes, C., Bernstein, I. L., Bernstein, J. A., Nel, A., Peden, D., Diaz-Sanchez, D., Tarlo, S. M., and Williams, P. B.: Health effects of air pollution, J. Allergy Clin. Immunol., 114, 1116-1123, doi:10.1016/j.jaci.2004.08.030, 2004.

Bertram, A. K., Ivanov, A. V., Hunter, M., Molina, L. T., and Molina, M. J.: The reaction probability of $\mathrm{OH}$ on organic surfaces of tropospheric interest, J. Phys. Chem. A, 105, 9415-9421, doi:10.1021/jp0114034, 2001.

Bey, I., Jacob, D. J., Yantosca, R. M., Logan, J. A., Field, B. D., Fiore, A. M., Li, Q. B., Liu, H. G. Y., Mickley, L. J., and Schultz, M. G.: Global modeling of tropospheric chemistry with assimilated meteorology: Model description and evaluation, J. Geophys. Res.-Atmos., 106, 23073-23095, 2001.

Broekhuizen, K. E., Thornberry, T., Kumar, P. P., and Abbatt, J. P. D.: Formation of cloud condensation nuclei by oxidative processing: Unsaturated fatty acids, J. Geophys. Res.-Atmos., 109, D24206, doi:10.1029/2004JD005298, 2004.

Cain, J. P., Gassman, P. L., Wang, H., and Laskin, A.: Micro-FTIR study of soot chemical composition-evidence of aliphatic hydrocarbons on nascent soot surfaces, Phys. Chem. Chem. Phys., 12, 5206-5218, doi:10.1039/b924344e, 2010

Chughtai, A., Miller, N., Smith, D., and Pitts, J.: Carbonaceous particle hydration III, J. Atmos. Chem., 34, 259-279, 1999.

Durant, J. L., Busby, W. F., Lafleur, A. L., Penman, B. W., and Crespi, C. L.: Human cell mutagenicity of oxygenated, nitrated and unsubstituted polycyclic aromatic hydrocarbons associated with urban aerosols, Mutat. Res.-Genet. Toxicol., 371, 123-157, 1996.

Dusanter, S., Vimal, D., Stevens, P. S., Volkamer, R., Molina, L. T., Baker, A., Meinardi, S., Blake, D., Sheehy, P., Merten, 
A., Zhang, R., Zheng, J., Fortner, E. C., Junkermann, W., Dubey, M., Rahn, T., Eichinger, B., Lewandowski, P., Prueger, J., and Holder, $\mathrm{H}$.: Measurements of $\mathrm{OH}$ and $\mathrm{HO}_{2}$ concentrations during the MCMA-2006 field campaign - Part 2: Model comparison and radical budget, Atmos. Chem. Phys., 9, 6655-6675, doi:10.5194/acp-9-6655-2009, 2009.

Eisenstat, S. C., Gursky, M. C., Schultz, M. H., and Sherman, A. H.: Yale Sparse Matrix Package: II. The Nonsymmetric Codes, 1977.

Eisenstat, S. C., Gursky, M. C., Schultz, M. H., and Sherman, A. H.: Yale Sparse Matrix Package: I. The Symmetric Codes, Int. J. Num. Meth. Eng., 18, 1145-1151, 1982.

El Haddad, I., Marchand, N., Dron, J., Temime-Roussel, B., Quivet, E., Wortham, H., Jaffrezo, J. L., Baduel, C., Voisin, D., Besombes, J. L., and Gille, G.: Comprehensive primary particulate organic characterization of vehicular exhaust emissions in France, Atmos. Environ., 43, 6190-6198, doi:10.1016/j.atmosenv.2009.09.001, 2009.

Emmerson, K. M., Carslaw, N., Carpenter, L. J., Heard, D. E., Lee, J. D., and Pilling, M. J.: Urban atmospheric chemistry during the PUMA campaign 1: Comparison of modelled $\mathrm{OH}$ and $\mathrm{HO}_{2}$ concentrations with measurements, J. Atmos. Chem., 52, 143164, doi:10.1007/s10874-005-1322-3, 2005.

Finlayson-Pitts, B. J.: Reactions at surfaces in the atmosphere: integration of experiments and theory as necessary (but not necessarily sufficient) for predicting the physical chemistry of aerosols, Phys. Chem. Chem. Phys., 11, 7760-7779, doi:10.1039/b906540g, 2009.

Finlayson-Pitts, B. J. and Pitts, J. N.: Tropospheric air pollution: Ozone, airborne toxics, polycyclic aromatic hydrocarbons, and particles, Science, 276, 1045-1052, 1997.

Finlayson-Pitts, B. J. and Pitts, J. N.: Chemistry of the upper and lower atmosphere, Academic Press, 525 B Street, Suite 1900, San Diego, CA, USA, 92101-4495, 1st edn., 2000.

Forster, P., Ramaswamy, V., Artaxo, P., Berntsen, T., Betts, R., Fahey, D., Haywood, J., Lean, J., Lowe, D., Myhre, G., Nganga, J., Prinn, R., Raga, G., Schulz, M., Van Dorland, R., and IPCC 2007: Climate Change 2007: The Physical Science Basis. Contribution of Working Group I to the Fourth Assessment Report of the Intergovernmental Panel on Climate Change, Cambridge University Press, Cambridge, UK and New York, NY, USA, http://www.ipcc.ch/publications_and_data/ar4/ wg1/en/contents.html, 2007.

Fuchs, N. A. and Sutugin, A. G.: High-dispersed aerosols, in: Topics in current aerosol research, edited by: Hidy, G. M. and Brock, J. R., Pergamon, New York, USA, 1-60, 1971.

Gerecke, A., Thielmann, A., Gutzwiller, L., and Rossi, M. J.: The chemical kinetics of HONO formation resulting from heterogeneous interaction of $\mathrm{NO}_{2}$ with flame soot, Geophys. Res. Lett., 25, 2453-2456, 1998.

Gross, S. and Bertram, A. K.: Reactive uptake of $\mathrm{NO}_{3}, \mathrm{~N}_{2} \mathrm{O}_{5}$, $\mathrm{NO}_{2}, \mathrm{HNO}_{3}$, and $\mathrm{O}_{3}$ on three types of polycyclic aromatic hydrocarbon surfaces, J. Phys. Chem. A, 112, 3104-3113, doi:10.1021/jp7107544, 2008.

Hallquist, M., Wenger, J. C., Baltensperger, U., Rudich, Y., Simpson, D., Claeys, M., Dommen, J., Donahue, N. M., George, C., Goldstein, A. H., Hamilton, J. F., Herrmann, H., Hoffmann, T., Iinuma, Y., Jang, M., Jenkin, M. E., Jimenez, J. L., KiendlerScharr, A., Maenhaut, W., McFiggans, G., Mentel, T. F., Monod,
A., Prévôt, A. S. H., Seinfeld, J. H., Surratt, J. D., Szmigielski, R., and Wildt, J.: The formation, properties and impact of secondary organic aerosol: current and emerging issues, Atmos. Chem. Phys., 9, 5155-5236, doi:10.5194/acp-9-5155-2009, 2009.

Harner, T. and Bidleman, T. F.: Octanol-air partition coefficient for describing particle/gas partitioning of aromatic compounds in urban air, Environ. Sci. Technol., 32, 1494-1502, 1998.

Hindmarsh, A. C.: ODEPACK, A Systematized Collection of ODE Solvers, in: Scientific Computing, edited by: Stepleman, R. S., Carver, M., and Peskin, R., Ames, W. F., and Vichnevetsky, R., North-Holland, Amsterdam, 55-64, 1983.

Huff Hartz, K. E., Rosenorn, T., Ferchak, S. R., Raymond, T. M., Bilde, M., Donahue, N. M., and Pandis, S. N.: Cloud condensation nuclei activation of monoterpene and sesquiterpene secondary organic aerosol, J. Geophys. Res.-Atmos., 110, doi:10.1029/2004JD005754, 2005.

Ivanov, A. V., Trakhtenberg, S., Bertram, A. K., Gershenzon, Y. M., and Molina, M. J.: $\mathrm{OH}, \mathrm{HO}_{2}$, and ozone gaseous diffusion coefficients, J. Phys. Chem. A, 111, 1632-1637, doi:10.1021/jp066558w, 2007.

Jimenez, J. L., Canagaratna, M. R., Donahue, N. M., Prévôt, A. S. H., Zhang, Q., Kroll, J. H., DeCarlo, P. F., Allan, J. D., Coe, H., Ng, N. L., Aiken, A. C., Docherty, K. S., Ulbrich, I. M., Grieshop, A. P., Robinson, A. L., Duplissy, J., Smith, J. D., Wilson, K. R., Lanz, V. A., Hueglin, C., Sun, Y. L., Tian, J., Laaksonen, A., Raatikainen, T., Rautiainen, J., Vaattovaara, P., Ehn, M., Kulmala, M., Tomlinson, J. M., Collins, D. R., Cubison, M. J., Dunlea, E. J., Huffman, J. A., Onasch, T. B., Alfarra, M. R., Williams, P. I., Bower, K., Kondo, Y., Schneider, J., Drewnick, F., Borrmann, S., Weimer, S., Demerjian, K., Salcedo, D., Cottrell, L., Griffin, R., Takami, A., Miyoshi, T., Hatakeyama, S., Shimono, A., Sun, J. Y., Zhang, Y. M., Dzepina, K., Kimmel, J. R., Sueper, D., Jayne, J. T., Herndon, S. C., Trimborn, A. M., Williams, L. R., Wood, E. C., Middlebrook, A. M., Kolb, C. E., Baltensperger, U., and Worsnop, D. R.: Evolution of Organic Aerosols in the Atmosphere, Science, 326, 1525-1529, doi:10.1126/science.1180353, 2009.

Kanakidou, M., Seinfeld, J. H., Pandis, S. N., Barnes, I., Dentener, F. J., Facchini, M. C., Van Dingenen, R., Ervens, B., Nenes, A., Nielsen, C. J., Swietlicki, E., Putaud, J., Balkanski, Y., Fuzzi, S., Horth, J., Moortgat, G. K., Winterhalter, R., Myhre, C. E. L., Tsigaridis, K., Vignati, E., Stephanou, E. G., and Wilson, J.: Organic aerosol and global climate modelling: a review, Atmos. Chem. Phys., 5, 1053-1123, doi:10.5194/acp-5-1053-2005, 2005.

Kashiwakura, K. and Sakamoto, K.: Emission Characteristics and Cancer Risks of Polycyclic Aromatic Hydrocarbon Emissions from Diesel-fueled Vehicles Complying with Recent Regulations, J. Health Sci., 56, 200-207, 2010.

Khoder, M. I.: Diurnal, seasonal and weekdays-weekends variations of ground level ozone concentrations in an urban area in greater Cairo, Environ. Monit. Assess., 149, 349-362, doi:10.1007/s10661-008-0208-7, 2009.

Kittelson, D. B., Watts, W. F., and Johnson, J. P.: On-road and laboratory evaluation of combustion aerosols-Part1: Summary of diesel engine results, J. Aerosol Sci., 37, 913-930, doi:10.1016/j.jaerosci.2005.08.005, 2006.

Kleffmann, J., Becker, K. H., Lackhoff, M., and Wiesen, P.: Het- 
erogeneous conversion of $\mathrm{NO}_{2}$ on carbonaceous surfaces, PCCP Phys. Chem. Chem. Phys., 1, 5443-5450, 1999.

Knopf, D. A., Mak, J., Gross, S., and Bertram, A. K.: Does atmospheric processing of saturated hydrocarbon surfaces by $\mathrm{NO}_{3}$ lead to volatilization?, Geophys. Res. Lett., 33, L17816, doi:10.1029/2006GL026884, 2006.

Knopf, D. A., Wang, B., Laskin, A., Moffet, R. C., and Gilles, M. K.: Heterogeneous nucleation of ice on anthropogenic organic particles collected in Mexico City, Geophys. Res. Lett., 37, L11803, doi:10.1029/2010GL043362, 2010.

Kolb, C. E., Cox, R. A., Abbatt, J. P. D., Ammann, M., Davis, E. J., Donaldson, D. J., Garrett, B. C., George, C., Griffiths, P. T., Hanson, D. R., Kulmala, M., McFiggans, G., Pöschl, U., Riipinen, I., Rossi, M. J., Rudich, Y., Wagner, P. E., Winkler, P. M., Worsnop, D. R., and O' Dowd, C. D.: An overview of current issues in the uptake of atmospheric trace gases by aerosols and clouds, Atmos. Chem. Phys., 10, 10561-10605, doi:10.5194/acp-10-10561-2010, 2010.

Kotamarthi, V. R., Gaffney, J. S., Marley, N. A., and Doskey, P. V.: Heterogeneous $\mathrm{NO}_{\mathrm{x}}$ chemistry in the polluted PBL, Atmos. Environ., 35, 4489-4498, 2001.

Kotzick, R., Panne, U., and Niessner, R.: Changes in condensation properties of ultrafine carbon particles subjected to oxidation by ozone, J. Aerosol. Sci., 28, 725-735, 1997.

Kroll, J. H., Donahue, N. M., Jimenez, J. L., Kessler, S. H., Canagaratna, M. R., Wilson, K. R., Altieri, K. E., Mazzoleni, L. R., Wozniak, A. S., Bluhm, H., Mysak, E. R., Smith, J. D., Kolb, C. E., and Worsnop, D. R.: Carbon oxidation state as a metric for describing the chemistry of atmospheric organic aerosol, Nat. Chem., 28, 133-139, doi:10.1038/nchem.948, 2011.

Kwamena, N. O. A., Thornton, J. A., and Abbatt, J. P. D.: Kinetics of surface-bound benzo[a]pyrene and ozone on solid organic and salt aerosols, J. Phys. Chem. A, 108, 11626-11634, doi:10.1021/jp046161x, 2004.

Liu, Y., Liu, C., Ma, J., Ma, Q., and He, H.: Structural and hygroscopic changes of soot during heterogeneous reaction with $\mathrm{O}_{3}$, Phys. Chem. Chem. Phys., 12, 10896-10903, doi:10.1039/c0cp00402b, 2010.

Maria, S. F., Russell, L. M., Gilles, M. K., and Myneni, S. C. B.: Organic aerosol growth mechanisms and their climate-forcing implications, Science, 306, 1921-1924, doi:10.1126/science.1103491, 2004.

Matthias, V., Aulinger, A., and Quante, M.: CMAQ simulations of the benzo(a)pyrene distribution over Europe for 2000 and 2001, Atmos. Environ., 43, 4078-4086, doi:10.1016/j.atmosenv.2009.04.058, 2009.

Molina, M. J., Ivanov, A. V., Trakhtenberg, S., and Molina, L. T.: Atmospheric evolution of organic aerosol, Geophys. Res. Lett., 31, L22104, doi:10.1029/2004GL020910, 2004.

Nguyen, M. L., Bedjanian, Y., and Guilloteau, A.: Kinetics of the reactions of soot surface-bound polycyclic aromatic hydrocarbons with $\mathrm{NO}_{2}$, J. Atmos. Chem., 62, 139-150, doi:10.1007/s10874-010-9144-3, 2009.

Nishino, J.: Adsorption of water Vapor and carbon dioxide at carboxylic functional groups on the surface of coal, Fuel, 80, 757764, 2001

Pakbin, P., Ning, Z., Schauer, J. J., and Sioutas, C.: Characterization of Particle Bound Organic Carbon from Diesel Vehicles Equipped with Advanced Emission Control Technologies, En- viron. Sci. Technol., 43, 4679-4686, doi:10.1021/es8030825, 2009.

Petters, M. D., Prenni, A. J., Kreidenweis, S. M., DeMott, P. J., Matsunaga, A., Lim, Y. B., and Ziemann, P. J.: Chemical aging and the hydrophobictohydrophilic conversion of carbonaceous aerosol, Geophys. Res. Lett., 33, doi:10.1029/2006GL027249, 2006.

Pöschl, U.: Formation and decomposition of hazardous chemical components contained in atmospheric aerosol particles, J. Aerosol Med.-Depos. Clear. Eff. Lung, 15, 203-212, 2002.

Pöschl, U.: Atmospheric aerosols: Composition, transformation, climate and health effects, Angew. Chem.-Int. Edit., 44, 7520 7540, doi:10.1002/anie.200501122, 2005.

Pöschl, U., Letzel, T., Schauer, C., and Niessner, R.: Interaction of ozone and water vapor with spark discharge soot aerosol particles coated with benzo[ $a$ ]pyrene: $\mathrm{O}_{3}$ and $\mathrm{H}_{2} \mathrm{O}$ adsorption, benzo $[a]$ pyrene degradation, and atmospheric implications, J. Phys. Chem. A, 105, 4029-4041, 2001.

Pöschl, U., Rudich, Y., and Ammann, M.: Kinetic model framework for aerosol and cloud surface chemistry and gas-particle interactions - Part 1: General equations, parameters, and terminology, Atmos. Chem. Phys., 7, 5989-6023, doi:10.5194/acp-75989-2007, 2007.

Ramanathan, V., Crutzen, P. J., Kiehl, J. T., and Rosenfeld, D.: Atmosphere - Aerosols, climate, and the hydrological cycle, Science, 294, 2119-2124, 2001.

Reisen, F. and Arey, J.: Atmospheric reactions influence seasonal PAH and nitro-PAH concentrations in the Los Angeles basin, Environ. Sci. Technol., 39, 64-73, 10.1021/es0354541, 2005.

Riemer, N., West, M., Zaveri, R. A., and Easter, R. C.: Simulating the evolution of soot mixing state with a particleresolved aerosol model, J. Geophys. Res.-Atmos., 114, D09202, doi:10.1029/2008JD011073, 2009.

Rogaski, C. A., Golden, D. M., and Williams, L. R.: Reactive uptake and hydration experiments on amorphous carbon treated with $\mathrm{NO}_{2}, \mathrm{SO}_{2}, \mathrm{O}_{3}, \mathrm{HNO}_{3}$, and $\mathrm{H}_{2} \mathrm{SO}_{4}$, Geophys. Res. Lett., 24, 381-384, 1997.

Rogge, W. F., Hildemann, L. M., Mazurek, M. A., Cass, G. R., and Simoneit, B. R. T.: Sources of Fine Organic Aerosol. 2. Noncatalyst and Catalyst-Equipped Automobiles and Heavy-Duty Diesel Trucks, Environ. Sci. Technol., 27, 636-651, 1993.

Rudich, Y.: Laboratory perspectives on the chemical transformations of organic matter in atmospheric particles, Chem. Rev., 103, 5097-5124, doi:10.1021/cr020508f, 2003.

Rudich, Y., Talukdar, R. K., Imamura, T., Fox, R. W., and Ravishankara, A. R.: Uptake of $\mathrm{NO}_{3}$ on $\mathrm{KI}$ solutions: rate coefficient for the $\mathrm{NO}_{3}+\mathrm{I}^{-}$reaction and gas-phase diffusion coefficients for $\mathrm{NO}_{3}$, Chem. Phys. Lett., 261, 467-473, 1996.

Rudich, Y., Donahue, N. M., and Mentel, T. F.: Aging of organic aerosol: Bridging the gap between laboratory and field studies, Annu. Rev. Phys. Chem., 58, 321-352, doi:10.1146/annurev.physchem.58.032806.104432, 2007.

Saathoff, H., Naumann, K. H., Riemer, N., Kamm, S., Mohler, O., Schurath, U., Vogel, H., and Vogel, B.: The loss of $\mathrm{NO}_{2}, \mathrm{HNO}_{3}$, $\mathrm{NO}_{3} / \mathrm{N}_{2} \mathrm{O}_{5}$, and $\mathrm{HO}_{2} / \mathrm{HOONO}_{2}$ on soot aerosol: A chamber and modeling study, Geophys. Res. Lett., 28, 1957-1960, 2001.

Seinfeld, J. H. and Pandis, S. N.: Atmospheric chemistry and physics, John Wiley \& Sons, Inc., 111 River Street, Hoboken, NJ 07030, USA, 2nd edn., 2006. 
Shilling, J. E., King, S. M., Mochida, M., and Martin, S. T.: Mass spectral evidence that small changes in composition caused by oxidative aging processes alter aerosol CCN properties, J. Phys. Chem. A, 111, 3358-3368, doi:10.1021/jp068822r, 2007.

Shiraiwa, M., Garland, R. M., and Pöschl, U.: Kinetic double-layer model of aerosol surface chemistry and gas-particle interactions (K2-SURF): Degradation of polycyclic aromatic hydrocarbons exposed to $\mathrm{O}_{3}, \mathrm{NO}_{2}, \mathrm{H}_{2} \mathrm{O}, \mathrm{OH}$ and $\mathrm{NO}_{3}$, Atmos. Chem. Phys., 9, 9571-9586, doi:10.5194/acp-9-9571-2009, 2009.

Shiraiwa, M., Pfrang, C., and Pöschl, U.: Kinetic multi-layer model of aerosol surface and bulk chemistry (KM-SUB): the influence of interfacial transport and bulk diffusion on the oxidation of oleic acid by ozone, Atmos. Chem. Phys., 10, 3673-3691, doi:10.5194/acp-10-3673-2010, 2010.

Shiraiwa, M., Sosedova, Y., Rouvière, A., Yang, H., Zhang, Y., Abbatt, J. P. D., Ammann, M., and Pöschl, U.: The role of long-lived reactive oxygen intermediates in the reaction of ozone with aerosol particles, Nat. Chem., 3, 291-295, doi:10.1038/nchem.988, 2011.

Smekens, A., Godoi, R. H. M., Berghmans, P., and Van Grieken, R. E.: Characterisation of soot emitted by domestic heating, aircraft and cars using diesel or biodiesel, J. Atm. Chem., 52, 4562, doi:10.1007/s10874-005-6903-7, 2005.

Springmann, M., Knopf, D. A., and Riemer, N.: Detailed heterogeneous chemistry in an urban plume box model: reversible co-adsorption of $\mathrm{O}_{3}, \mathrm{NO}_{2}$, and $\mathrm{H}_{2} \mathrm{O}$ on soot coated with benzo[ $[a]$ pyrene, Atmos. Chem. Phys., 9, 7461-7479, doi:10.5194/acp-9-7461-2009, 2009.

Tabor, K., Gutzwiller, L., and Rossi, M. J.: Heterogeneous chemical kinetics of $\mathrm{NO}_{2}$ on amorphous carbon at ambient temperature, J. Phys. Chem., 98, 6172-6186, 1994.
Tie, X., Brasseur, G., Emmons, L., Horowitz, L., and Kinnison, D.: Effects of aerosols on tropospheric oxidants: A global model study, J. Geophys. Res.-Atmos., 106, 22931-22964, 2001.

Vione, D., Barra, S., De Gennaro, G., De Rienzo, M., Gilardoni, S., Perrone, M. G., and Pozzoli, L.: Polycyclic aromatic hydrocarbons in the atmosphere: monitoring, sources, sinks and fate. II: Sinks and fate, Ann. Chim., 94, 257-268, 2004.

Wang, J., Cubison, M. J., Aiken, A. C., Jimenez, J. L., and Collins, D. R.: The importance of aerosol mixing state and size-resolved composition on $\mathrm{CCN}$ concentration and the variation of the importance with atmospheric aging of aerosols, Atmos. Chem. Phys., 10, 7267-7283, doi:10.5194/acp-10-7267-2010, 2010.

Weingartner, E., Burtscher, H., and Baltensperger, U.: Hygroscopic properties of carbon and diesel soot particles, Atmos. Environ., 31, 2311-2327, 1997.

Zaveri, R. A. and Peters, L. K.: A new lumped structure photochemical mechanism for large-scale applications, J. Geophys. Res.Atmos., 104, 30387-30415, 1999.

Zaveri, R. A., Easter, R. C., and Peters, L. K.: A computationally efficient multicomponent equilibrium solver for aerosols (MESA), J. Geophys. Res.-Atmos., 110, D24203, doi:10.1029/ 2004JD005618, 2005a.

Zaveri, R. A., Easter, R. C., and Wexler, A. S.: A new method for multicomponent activity coefficients of electrolytes in aqueous atmospheric aerosols, J. Geophys. Res.-Atmos., 110, D02201, doi:10.1029/2004JD004681, 2005b.

Zaveri, R. A., Easter, R. C., Fast, J. D., and Peters, L. K.: Model for Simulating Aerosol Interactions and Chemistry (MOSAIC), J. Geophys. Res.-Atmos., 113, D13204, doi:10.1029/2007JD008782, 2008. 